\title{
Mobilization of retrotransposons as a cause of chromosomal diversification and rapid speciation: the case for the Antarctic teleost genus Trematomus
}

\author{
J. Auvinet ${ }^{1,3^{*}}$ D, P. Graça ${ }^{1}$, L. Belkadi ${ }^{4}$, L. Petit ${ }^{2}$, E. Bonnivard ${ }^{1}$, A. Dettaï ${ }^{3}$, W. H Detrich $\|^{5}{ }^{5}$, C. Ozouf-Costaz ${ }^{1}$
} and D. Higuet $^{1}$

\begin{abstract}
Background: The importance of transposable elements (TES) in the genomic remodeling and chromosomal rearrangements that accompany lineage diversification in vertebrates remains the subject of debate. The major impediment to understanding the roles of TEs in genome evolution is the lack of comparative and integrative analyses on complete taxonomic groups. To help overcome this problem, we have focused on the Antarctic teleost genus Trematomus (Notothenioidei: Nototheniidae), as they experienced rapid speciation accompanied by dramatic chromosomal diversity. Here we apply a multi-strategy approach to determine the role of large-scale TE mobilization in chromosomal diversification within Trematomus species.

Results: Despite the extensive chromosomal rearrangements observed in Trematomus species, our measurements revealed strong interspecific genome size conservation. After identifying the DIRS1, Gypsy and Copia retrotransposon superfamilies in genomes of 13 nototheniid species, we evaluated their diversity, abundance (copy numbers) and chromosomal distribution. Four families of DIRS1, nine of Gypsy, and two of Copia were highly conserved in these genomes; DIRS1 being the most represented within Trematomus genomes. Fluorescence in situ hybridization mapping showed preferential accumulation of DIRS1 in centromeric and pericentromeric regions, both in Trematomus and other nototheniid species, but not in outgroups: species of the Sub-Antarctic notothenioid families Bovichtidae and Eleginopsidae, and the non-notothenioid family Percidae.

\footnotetext{
* Correspondence: juliette.auvinet@etu.sorbonne-universite.fr

${ }^{1}$ Laboratoire Evolution Paris Seine, Sorbonne Université, Univ Antilles, CNRS, Institut de Biologie Paris Seine (IBPS), F-75005 Paris, France

${ }^{3}$ Institut de Systématique, Evolution, Biodiversité (ISYEB), Museum National d'Histoire Naturelle, CNRS, Sorbonne Université, EPHE, 57, rue Cuvier, 75005 Paris, France

Full list of author information is available at the end of the article
}

(c) The Author(s). 2018 Open Access This article is distributed under the terms of the Creative Commons Attribution 4.0 International License (http://creativecommons.org/licenses/by/4.0/), which permits unrestricted use, distribution, and reproduction in any medium, provided you give appropriate credit to the original author(s) and the source, provide a link to the Creative Commons license, and indicate if changes were made. The Creative Commons Public Domain Dedication waiver (http://creativecommons.org/publicdomain/zero/1.0/) applies to the data made available in this article, unless otherwise stated. 
(Continued from previous page)

Conclusions: In contrast to the outgroups, High-Antarctic notothenioid species, including the genus Trematomus, were subjected to strong environmental stresses involving repeated bouts of warming above the freezing point of seawater and cooling to sub-zero temperatures on the Antarctic continental shelf during the past 40 millions of years (My). As a consequence of these repetitive environmental changes, including thermal shocks; a breakdown of epigenetic regulation that normally represses TE activity may have led to sequential waves of TE activation within their genomes. The predominance of DIRS1 in Trematomus species, their transposition mechanism, and their strategic location in "hot spots" of insertion on chromosomes are likely to have facilitated nonhomologous recombination, thereby increasing genomic rearrangements. The resulting centric and tandem fusions and fissions would favor the rapid lineage diversification, characteristic of the nototheniid adaptive radiation.

Keywords: Trematomus, Chomosomal rearrangements, Speciation, Nototheniidae, Retrotransposons, FISH, DIRSI insertion hot spots

\section{Background}

Chromosomal changes are considered by many as a major driving force behind speciation [1-3]. They are major sources of accumulation of genetic incompatibilities, and their fixation is the first stage toward complete reproductive isolation $[4,5]$. Through recombination events [6, 7], transposable element (TE) activity can lead to chromosomal rearrangements $[2,8,9]$ that may drive lineage-specific diversification $[1,10]$, although the relative importance of TE-mediated rearrangements to speciation continues to be debated [11, 12]. Therefore, the characterization of TE content and chromosomal organization among diverging lineages in natural specie ensembles is an essential step toward understanding the role of mobile elements in species diversification.

TEs are major components of eukaryote genomes: they impact genome structure and plasticity $[7,13,14]$, generating genetic variability on which different evolutionary forces can act [15]. Depending on their mode of transposition, TEs are divided in two categories: the DNA transposons (class II) move through a "cut-andpaste" mechanism, whereas the retrotransposons (class I) replicate via a "copy-and-paste" process involving an RNA intermediate. Five major orders of class I TEs have been identified [16]: Long INterspersed Elements (LINEs), Short INterspersed Elements (SINEs), Penelope (PLEs), Long Terminal Repeat (LTR) retrotransposons and tYrosine Recombinase (YR) encoding elements (also known as DIRS, Dictyostelium Intermediate Repeat Sequence). Within each order, TEs have been categorized in different superfamilies. In animal genomes, the Gypsy, Copia and BEL/Pao superfamilies of the LTR order are the most widely distributed and diversified [17-19]. These elements are flanked by two direct LTRs that encompass the promoter and regulatory regions. Between the LTRs two open reading frames (ORFs) are usually found [20]: 1) gag, encoding virus-like particles; and 2) pol, encoding a reverse transcriptase (RT), an RNase $\mathrm{H}(\mathrm{RH})$, and an integrase (INT), necessary for insertion activity. The pol region of DIRS elements are generally similar to LTR retrotransposons, except for the substitution of a tyrosine recombinase ORF for the integrase ORF of LTRs. The DIRS order contains Ngaro, VIPER, and DIRS superfamilies; the last is further subdivided into DIRS1 and PAT elements. In contrast to LTR retrotransposons found in a wide continuum of species, DIRS elements have a more patchy taxonomic distribution [21]. While DIRS are absent in model organisms, they have been detected in teleosts (Danio rerio and Takifugu rubripes) [22-25]. Moreover, the small number of DIRS families in the species genomes $[26,27]$ stands in strong contrast to the abundant representation of LTR families [16, 28-30].

Bursts of TE activity and amplification in the genomes of plants [9], D. melanogaster [31], and vertebrates $[10,13,32]$ are known to have participated in speciation events [33], for example by promoting genomic destabilization and incompatibilities (postzygotic barriers) in hybrid generations [34]. Furthermore, environmental changes, including thermal stress, can cause the breakdown of the epigenetic control that normally represses TE activity [35]. This may cause massive bursts of transposition during species radiations $[3,32,36]$. The activation and mobility of TEs increase chromosomal diversification and potentially speciation rate in some groups, as shown in D. melanogaster [37-39], in maize [40], and in primates [41]. However, integrative analyses of chromosomal rearrangements and their linkage to retrotransposition in complete taxonomic groups have in general been hindered by lack of the requisite molecular, chromosomal and environmental data.

During the last 40 millions of years $(M y)$, the Antarctic fauna have experienced multiple glacial-interglacial cycles, leading to habitat disturbance by iceberg scouring and habitat fragmentation during glacial maxima [42-44]. The Antarctic teleosts fish family Nototheniidae (antifreeze glycoprotein-(AFGP-) producing "cod icefishes" [45]) 
rapidly diversified into several species flocks and now constitute the dominant group of Antarctic teleosts [45-47] with well-documented phylogenetic relationships $[45,48-50]$. The nototheniid genus Trematomus (including Indonotothenia cyanobrancha [50]) is an example of a relatively recent (-9.1 My [45]; - 4.3 $M y$ [51]) and rapid marine adaptive radiation. All are endemic to coastal waters of the Antarctic continental shelf. Although their ancestral diploid karyotype was inferred to have 48 acrocentric chromosomes (the typical karyotype of most modern teleosts), trematomines exhibit the highest chromosomal diversity among the Nototheniidae [52, 53]. Diploid chromosome numbers range between 24 and 58 , and chromosomal rearrangements of all types are plentiful [54-56], which is rare among other marine teleosts [57]. Sex chromosome differentiation also occurred via genomic restructuring $[4,52,53,55]$, as at least five Trematomus species possess a multiple sex chromosome system of the female X1X1X2X2 / male $\mathrm{X} 1 \mathrm{X} 2 \mathrm{Y}$ type. Males have an odd chromosome number due to the tandem fusion between one $\mathrm{X} 1$ and one $\mathrm{X} 2$ autosome to form the $\mathrm{Y}$ element.

The tractable species number of the monophyletic genus Trematomus, the history of thermal perturbations of the taxon, its remarkable inter- and intraspecific chromosomal diversity, and its plethora of TEs [58-62] make the group ideal to investigate whether mobilization of TEs in response to environmental change may have played a role in the chromosomal diversification that often accompanies rapid speciation events. In the present multi-strategy study, we focus on DIRS- and LTR-order retrotransposons, specifically the diversity, distribution, chromosomal locations, and quantification of the pol region of the DIRS1, Gypsy, and Copia elements, which we find to be widely distributed in the genomes of Trematomus and other nototheniid species. The results obtained were compared to related temperate and Sub-Antarcic non AFGP-bearing species that have not experienced such environmental changes.

\section{Results}

\section{Genome sizes estimations}

We determined a mean genome size of $1.19 \pm 0.12 \mathrm{pg}$ (s. e.m.) for Trematomus species, with $\mathrm{C}$-values ranging from 1.09 to $1.26 \mathrm{pg}$. Our values from the nototheniids D. mawsoni $(1.02 \mathrm{pg})$ and $N$. coriiceps $(1.36 \mathrm{pg})$ flanked the trematomine range. Variance between technical triplicates $(0.015 \mathrm{pg}$, s.e.m.) and biological triplicates $(0.017 \mathrm{pg}$, s.e.m.) were correspondingly low (one to seventeen specimens per species, see Additional file 1). In general, our results are in close agreement with those $\mathrm{C}$-values published previously (Table 1 ).

\section{Nototheniid retrotransposons: Identification, genomic distribution and characterization}

Four families of DIRS1 (named YNotoJ, $V, B$ and $R$ ) have been identified based on the $1.25 \mathrm{~kb}$ fragments overlapping the RT/RH domains. For the Gypsy elements, nine families (named GyNotoA, $B, D, E, F, H, I, J, R T$ ) have been identified; five with $1.5 \mathrm{~kb}$ fragments than span the $\mathrm{RT} / \mathrm{RH} / \mathrm{INT}$ domains (region 2), the other four with $0.6 \mathrm{~kb}$ fragments overlapping the RT/RH or the INT domain (region 1 or 3 ), as it was not possible to extend the seed by TE-walking. Two families of Copia (named CoNotA and CoNotoB) were detected with sequences of 1 or $1.4 \mathrm{~kb}$

Table 1 C-values (pg) of nototheniid species

\begin{tabular}{|c|c|c|c|c|c|}
\hline Sub-families & Genus. species (abbreviation) & Chromosomal numbers (2n) & No. examined & C-values $(p g) \pm S E$ & Prior published results (ref) \\
\hline \multirow[t]{11}{*}{ Trematominae } & T. eulepidotus (Teu) & 24 & 1 & 1.26 & \\
\hline & T. pennellii (Tpe) & 32 & 1 & 1.15 & \\
\hline & T. borchgrevinki (Tbo) & $\underline{45-46^{a}}$ & 8 & $1.09 \pm 0.039$ & $1.28[116]$ \\
\hline & T. hansoni (Tha) & $\underline{45-46 / 46 / 48^{a}}$ & 12 & $1.26 \pm 0.025$ & \\
\hline & T. bernacchii (Tbe) & 48 & 17 & $1.12 \pm 0.019$ & $1.20[73,117]$ \\
\hline & T. loennbergii (Tlo) & $\underline{47-48^{a}}$ & 1 & 1.34 & \\
\hline & T. lepidorhinus (Tle) & $\underline{47-48}{ }^{a}$ & 0 & ND & \\
\hline & T. newnesi (Tne) & $\underline{45-46}^{\mathrm{a}}$ & 2 & $1.15 \pm 0.141$ & $1.01[60]$ \\
\hline & T. scotti (Tsc) & 48 & 0 & ND & \\
\hline & T. nicolaï (Tni) & $\underline{57-58}^{a}$ & 2 & $1.17 \pm 0.04$ & \\
\hline & I. cyanobrancha (Icy) & 48 & 0 & ND & \\
\hline Nototheniinae & N. coriiceps (Nco) & 22 & 3 & $1.36 \pm 0.118$ & $1.13[60]$ \\
\hline Dissostichinae & D. mawsoni (Dma) & 48 & 3 & $1.02 \pm 0.016$ & $0.97[116] ; 1.03[73,117] ; 1.20[60]$ \\
\hline
\end{tabular}

${ }^{\mathrm{a}}$ Several different karyotypes per species due to sex chromosome differentiation (either an X1X1X2X2 female or an X1X2Y male). The possible combinations from our sampling are underlined 
overlapping either the RT/RH or the RT/RH/INT domains (Table 2). All identified TE families appeared ubiquitous, in all investigated genomes, with three exceptions: GyNotoD and GyNotoJ, only detected in one or two genomes; and CoNotoA not detected in Trematomus genomes (Additional file 2).

All TE families sequenced showed a strong intrafamily conservation across nototheniid species. We found a high nucleotide sequence identity within each DIRS1 family (88.2 to $91.4 \%$ ) (Table 3a), as well as within each Gypsy family ( 88.3 to $96.6 \%$ for the fragments that span the RT/RH portion and 89.7 to $97.8 \%$ for the fragments overlapping on INT portion) (Table 3b). Copia sequences within a family were similarly conserved (95.9 to $98.5 \%$ ) (Table 3c).

The maximum divergence between TE families across nototheniid species was $50.3 \%$ for DIRS1, followed by $37.8 \%$ interfamily divergence for Gypsy. CoNotoA (GalEa) and CoNotoB (Hydra) could not be reliably aligned for comparison.

\section{Nototheniid retrotransposon positioning among eukaryote TEs}

We ran phylogenetic analyses for DIRS1, Gypsy and Copia TEs in order to position our TE family among TE families described in eukaryote genomes. The same topologies were observed whether Distance or Maximum Likelihood reconstruction methods were used. The large majority of our sequences cluster together with sequences previously described in bony fish or vertebrate

Table 2 Characteristics of the DIRS1, Gypsy and Copia sequences (TE dataset) detected in nototheniid genomes

\begin{tabular}{llll}
\hline TE superfamily & Family & Amplification size $(\mathrm{kb})^{1}$ & Region $^{2}$ \\
\hline DIRS1 (YNoto) & YNotoJ & 1.25 & 1 \\
& YNotoV & 1.26 & 1 \\
& YNotoB & 1.25 & 1 \\
& YNotoR & 1.25 & 1 \\
Gypsy (GyNoto) & GyNotoA & 1.54 & 2 \\
& GyNotoB & 1.54 & 2 \\
& GyNotoD & 1.55 & 2 \\
& GyNotoE & 1.62 & 2 \\
& GyNotoF & 0.61 & 3 \\
& GyNotoH & 0.61 & 3 \\
& GyNotol & 0.61 & 3 \\
& GyNotoJ & 1.22 & 2 \\
& GyNotoRT & 0.65 & 1 \\
& CoNotoA & 0.94 & 1 \\
& ConotoB & 1.38 & 2 \\
\hline
\end{tabular}

${ }^{1}$ Size of TE consensus from each family found in nototheniid genomes. ${ }^{2}$ Either for DIRS1, Gypsy or for Copia elements, we focused on the pol region. The TE sequences are then overlapping on 1: RT/RH, 2: RT/RH/INT or 3: INT domains groups (Figs. 1, 2, and 3, Additional files 3, 4, and 5 for full trees). DIRS1 nototheniid consensus sequences cluster with other bony fish DIRS1 sequences from Tetraodon nigroviridis, Gasterosteus aculeatus, Danio rerio, and Oryzias latipes (0.96 support). Except for GyNotoI and GyNotoRT, Gypsy nototheniid consensus sequences cluster with other vertebrate and bony fish Gypsy sequences from Tetraodon rubripes and Danio rerio (0.62 and 0.69 support, respectively). Copia nototheniid consensus sequences cluster with other bony fish - GalEa sequences for CoNotoA or Hydra sequences for CoNotoB - from Danio rerio, Dicentrarchus labrax and Oreochromis niloticus (support $=1$ ) (Figs. 1, 2a, b and 3).

All DIRS1 consensus were positioned among the described "FISH cluster" ("DrDIRS1" group) [23, 24, 27]. $Y N o t o J$ and YNotoV seemed to be more closely related between each other than with YNotoR and YNotoB (Fig. 1). In the same way, GyNotoB and GyNotoD were closely related but no nototheniid Gypsy clade was detected: all GyNoto consensus sequences (except GyNotoI and RT) were grouped with other Gypsy sequences from $T$. rubripes and from $D$. rerio belonging to the described "V cluster" [63] (Fig. 2). GyNotoI and GyNotoRT even fell outside the bony fish TE clade (Additional file 4) and were much more difficult to align than the other family consensus sequences. Finally, the two CoNoto consensus sequences were placed within two distinct Copia bony fish sub-clades, both closely related to Copia sequences found in the zebrafish D. rerio: Hydra1-2 for CoNotoB and GalEaZeco1 for CoNotoA (Fig. 3).

\section{Chromosomal location of nototheniid retrotransposon families}

Fluorescent In Situ hybridization (FISH) is a powerful technology for imaging the distribution of repetitive gene families on the condensed chromosomes of metaphase spreads. To assess the potential role of nototheniid TEs in mediating chromosomal rearrangements in Trematomus and other High Antarctic species, we used FISH to map the locations of two families of DIRS1, two families of Gypsy, and one family of Copia (Hydra) on chromosome preparations from five nototheniid species that represent the diversity of nototheniid karyotypes ( $2 \mathrm{n}=22$ metacentrics to $2 \mathrm{n}=48$ acrocentrics): $T$. eulepidotus, T. hansoni, T. pennellii, N. coriiceps, and D. mawsoni. For comparison, we chose chromosome preparations from three cool temperate/temperate outgroup species: the Sub-Antarctic notothenioids $B$. diancanthus and E. maclovinus, and the Eurasian perch P. fluviatilis, all of which feature 48 acrocentric chromosomes. The TE families were chosen for their cloned sequence sizes $(>1 \mathrm{~kb})$ and their ubiquity in the genomes of nototheniid species (Additional files 2 and 6). Figure 4 shows the 
Table 3 Nucleic acid identity matrices of DIRS1 (a), Gypsy (b) and Copia (c) families across nototheniid species

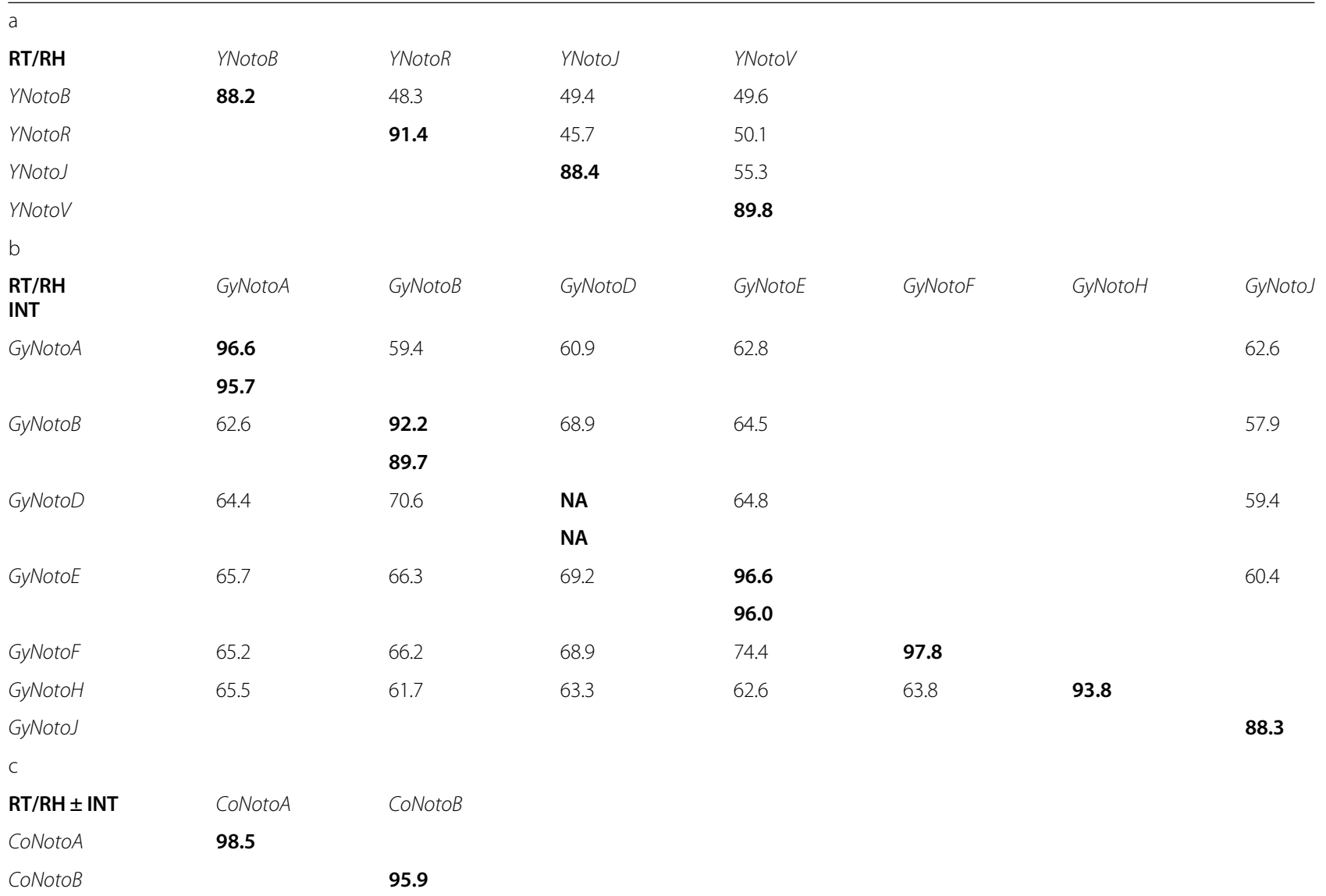

Note - Identity percentages are based on the nucleotide sequence alignments of identified nototheniid retrotransposons (see Additional file 9 for taxonomic sampling).TE intrafamily percentage identies across nototheniid species are indicated in bold. For Gypsy elements, identities calculated from RT/RH are presented above the table diagonal line and those based on INT are shown below. NA: not applicable because only one sequence identified for the family

two major types of TE distribution patterns: (1) dense accumulation ("hot spots") mainly in centromeric and/or pericentromeric regions and sometimes in intercalary or telomeric positions; and (2) scattered, punctuate staining along chromosome arms. Combinations of these two patterns were also evident. The distributions (1) and/or (2) clearly depended upon the TE super-family, but within a super-family, different TE families produced comparable results (e.g., the nearly identical patterns observed between YNotoJ and YNotoR of the DIRS1 superfamily as shown with the double FISH-mapping (Additional files 7 and 8),

Table 4 TE copy numbers estimated in the nototheeniid genomes

\begin{tabular}{lllllll}
\hline TEs & DIRS1 & DIRS1 & DIRS1 & Gypsy & Gypsy & Copia \\
Species & YNotoJ & YNotoV & YNotoRB & GyNotoA & GyNotoE & CoNotoB \\
\hline T. pennellii & 370 & 110 & 125 & 50 & 8 & 45 \\
T. hansoni & 275 & 200 & 30 & 90 & 30 & 45 \\
T. eulepidotus & 250 & 80 & 55 & 45 & 7 & 15 \\
N. coriiceps & 80 & 135 & 15 & 8 & 20 & 10 \\
D. mawsoni & 120 & 340 & 10 & 20 & 7 & 10 \\
\hline
\end{tabular}

and between GyNotoA and GyNotoE of the Gypsy superfamily) (Fig. 4 and Additional file 7). For a given TE family, there were small variations of signal intensity or distribution along chromosomes between species, but generally, the same location pattern was observed.

The two investigated families of Gypsy and Copia Hydra elements were mostly dispersed throughout nototheniid chromosome arms (type 2), forming multiple spots scattered everywhere on nototheniid chromosome arms ( $T$. pennellii, T. eulepidotus, $N$. coriiceps and D. mawsoni) as well as in centromeres and telomeres of acrocentric ( $T$. hansoni, T. pennellii and D. mawsoni) and metacentric ( $T$. eulepidotus, T. pennellii and $N$. coriiceps) chromosomes. Signals occasionally accumulated on metacentric chromosomes (giving a type $1+2$ pattern) (Fig. $4 \mathrm{e}, \mathrm{j}, \mathrm{p}$ ). In the nototheniid species, the two FISH-investigated families of DIRS1 elements appeared to accumulate (white arrows in Fig. 4 and Additional file 7) in centromeric regions (type 1), mostly in short acrocentric pairs (Fig. 4d, n), in some telomeres (Fig. $4 \mathrm{~d}, \mathrm{~h}$ ) and were also aggregated in pericentromeric areas (type 1), especially in karyotypes with metacentric chromosomes (Fig. 4h, k). The DIRS1 element 

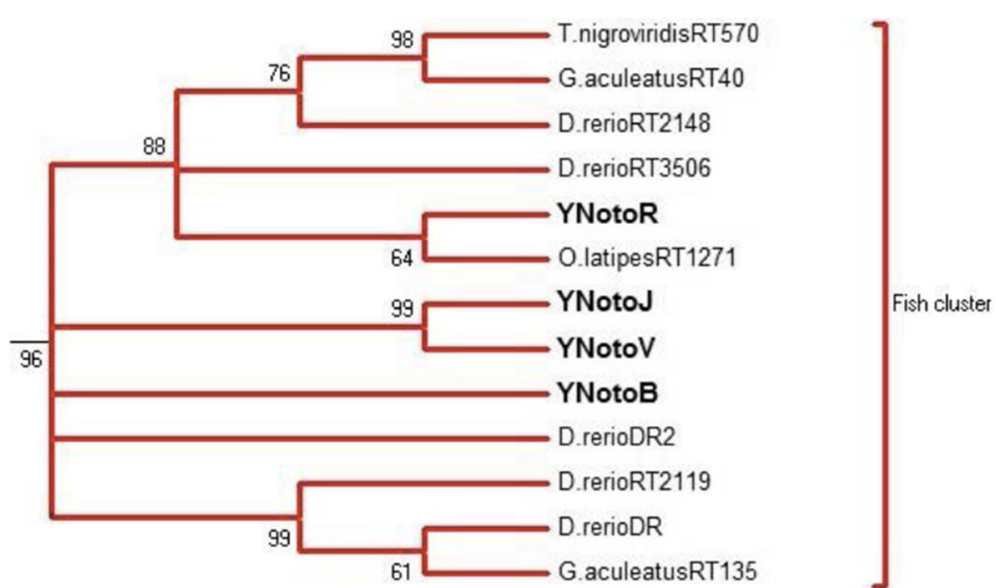

Fig. $1 \mathrm{NJ}$ bootstrap consensus tree for DIRS1 based on the RT/RH amino acid sequences. Only the branch containing the nototheniid DIRS1 families and the closest related sequences are shown. The four nototheniid DIRS1 families (bold font) group with the other bony fish sequences: Tetraodon nigroviridis, Gasterosteus aculeatus, Danio rerio, Oryzias latipes. Distances were calculated with the JTT model and a gamma distribution correction for amino acid. Support for individual clusters was evaluated using non-parametric bootstrapping with 1000 replicates. Only bootstraps over 60 are presented. Nodes with bootstraps $<60 \%$ were collapsed. See full tree in Additional file 3

pattern (type 1) was very distinct from the Gypsy and Copia patterns, with clear hot spots of insertion in all nototheniid species studied. In contrast, these DIRS1 hot spots were not detected in the three outgroups B. diancantus, E. maclovinus and $P$. fluviatilis, where FISH signals were mostly scattered on chromosome arms (type 2), with some of them located on telomeres, but never aggregated. Even if the Gypsy and Copia FISH signals seemed less abundant, they were still scattered on chromosome arms (type 2) like for the five High Antarctic species (Fig. 5).

\section{Retrostransposon quantification}

The same five TE families (YNotoJ, YNotoR, GyNotoA, GyNotoE, CoNotoB) were quantified in the same five nototheniid species ( $T$. pennellii, T. hansoni, T. eulepidotus, N. coriiceps, D. mawsoni) using qPCR. Our quantification results indicated that Gypsy and Copia elements were present in 7-90 copies per family studied, while DIRS1 elements were generally represented by 100-150 copies per family in the five genomes (Table 4). For the DIRS1 retrotransposons, YNotoJ and YNotoV appeared the most represented families in T. hansoni, $T$. eulepidotus, $N$. coriiceps and D. mawsoni genomes. In $T$. pennellii, we estimated 370 YNotoJ but a roughly equal number for YNotoV (110) and YNotoRB (125). The GyNotoA (between 10 and 90 copies) were more represented than GyNotoE (<10 copies, apart from for $T$. hansoni, with an estimate of 30 copies detected) except in N. coriiceps (8 GyNotoA vs 20 GyNotoE). T. pennellii carried the highest number of DIRS1 retrotransposons when counting all families together (total of 605 estimated copies) and T. hansoni, the highest number of

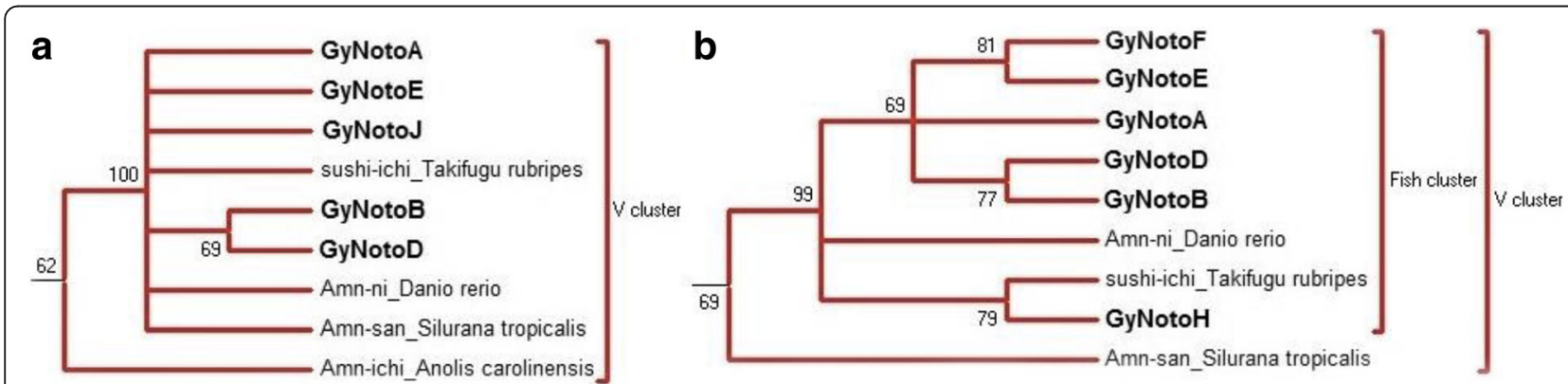

Fig. 2 NJ bootstrap consensus tree for Gypsy based on the RT/RH (a), INT (b) regions. Only the branch containing the nototheniid Gypsy and the closest related amino acid sequences are presented. Except for GyNotol and GyNotoRT, the seven nototheniid Gypsy families shown (bold font) group with bony fish sequences: Takifugu rubripes -sushi-ichi and Danio rerio -Amn-ni in addition to other vertebrate Gypsy sequences: Xenopus/ Silurana tropicalis. Distances were calculated with the JTT model and a gamma distribution correction for amino acid. Support for individual clusters was evaluated using non-parametric bootstrapping with 1000 replicates. Only bootstraps over 60 are presented. Nodes with bootstraps < $60 \%$ were collapsed. See full tree in Additional file 4 


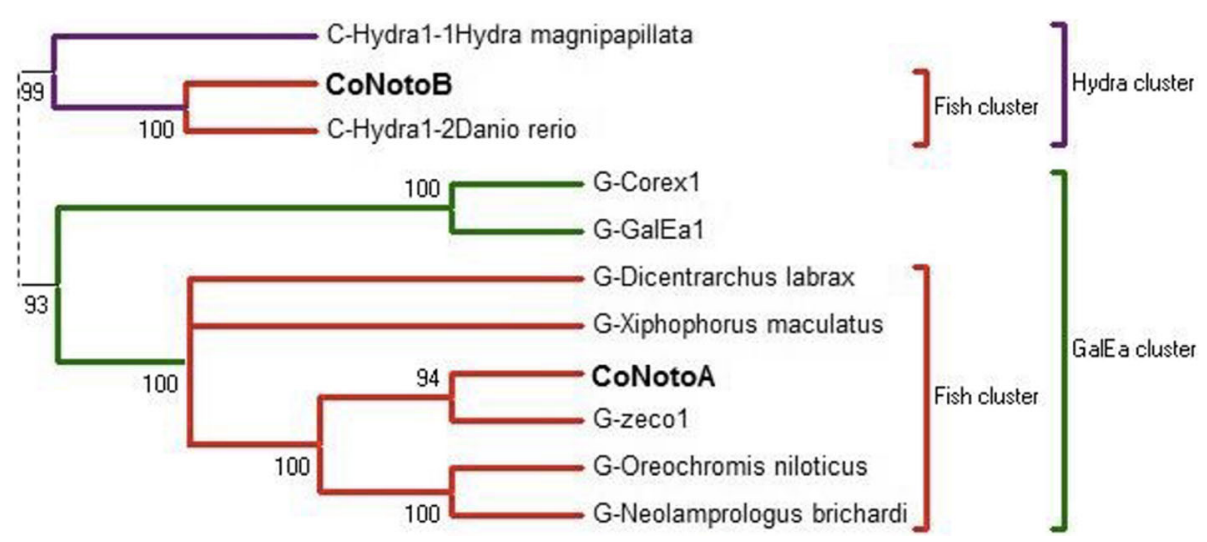

Fig. $3 \mathrm{NJ}$ bootstrap consensus tree for Copia based on the RT/RH amino acid sequences. Only the branch containing the nototheniid Copia families and the closest related sequences are shown. The two nototheniid Copia families (bold font) identified in nototheniid genomes group with bony fish sequences: Dicentrarchus labrax, Xiphophorus maculatus, Danio rerio, Oreochromis niloticus and Neolamprologus brichardi. Distances were calculated with the JTT model and the gamma distribution correction for amino acid. Support for individual clusters was evaluated using non-parametric bootstrapping with 1000 replicates. Only bootstraps over 60 are presented. Nodes with bootstraps $<60 \%$ were collapsed. See full tree in Additional file 5

Gypsy elements (total of 120 estimated copies). Both of those genomes also contained the highest copy number for Copia Hydra elements (45 estimated copies) whereas we estimated a low number of copies, 10 to 15 for the other three species $T$. eulepidotus, $N$. coriiceps and $D$. mawsoni.

\section{Discussion \\ TE diversity}

Our investigation revealed a high diversity of retrotransposons within nototheniid genomes, with four families of DIRS1, nine of Gypsy and two of Copia identified. This result corroborates previous studies on the large number and repartition of TEs in teleost species [19, 64, 65]. Within nototheniid species, Detrich et al. [60] have described TEs in Notothenia coriiceps and Chaenocephalus aceratus from partial genome sequencing data, finding respectively 13.4 and $14.5 \%$ of their genomes composed of a wide TE diversity. Retrotransposons seem more represented than DNA transposons.

The present study shows retrotransposon sequence conservation between species, with levels of interspecific nucleotide identity similar to those observed between Trematomus species for Rex 1 and Rex3 non-LTR retrotransposons [59], or for nuclear coding genes like Pkd1 (98.4\%), RPS71 (98.2\%) and Rhodopsin (98.9\%) [45, 50]. This result suggests that these TEs are subject to strong selective pressure to maintain their activity $[65,66]$. They also show that transposition events may have occurred recently in those genomes. These observations might be subject to some biases due to the method employed to detect the conserved domains on pol region and thus, preferentially potentially active, or recently active TEs.
The presence of twelve of the fifteen identified TE families in all the studied genomes points to a divergence of the TE families prior to the divergence of the nototheniid species [58]. Our sampling includes species representing the oldest divergence in the family, estimated between 22.4 and - 13.4 My depending on the study [45, 51]. Their mobilization in the genomes however could have occurred more recently, perhaps during nototheniid radiation events.

Although our nototheniid TE consensus sequences belong systematically to the Vertebrate or the fish clade, they are not grouped together like in other studies [59]. All species studied were found to contain at least one copy of each identified TE family, except two families of Gyspy (GyNotoD, and GyNotoJ) and one of Copia GalEa (CoNotoA). This last family was not recovered in the genus Trematomus, but it was successfully amplified in $N$. coriiceps, $D$. mawsoni and other Nototheniidae (Additional file 2). We extended the search for GalEa to other trematomine species closely related to Trematomus: genera Indonotothenia, Lepidonotothen and Patagonotothen without being able to successfully amplify them by PCR. We are aware that a lack of PCR amplification of a given DNA fragment does not mean it is absent from the genome examined. However, given the strong interspecific conservation of GalEa family in nototheniids and the tendency of GalEa elements to be secondary lost in entire clades (for example within Fungal and Crustacean genomes $[67,68])$, this would indicate the presence of GalEa retrotransposons in the last common ancestor of all Nototheniidae was followed by a secondary loss in Trematominae. Such result supports recent phylogenetic studies grouping together the genera Cryothenia, Indonotothenia, Pagothenia, 
Trematomus, Lepidonotothen and Patagonothen in the Trematominae sub-family [45, 48-51, 69, 70].

\section{Extensive chromosomal rearrangements and conserved genome size within the Trematomus}

Trematomus $\mathrm{C}$-values for the different studied species are very close to each other (1.0 to $1.2 \mathrm{pg}$ ). They fall also in the same range as the values obtained or published for other nototheniid sub-family representatives: Notothenia (N. coriiceps, $1.36 \mathrm{pg}$ [60]), Dissostichus (D. mawsoni, $1.02 \mathrm{pg}$ [60]), Lepidonotothen (Lepidonotothen nudifrons, $1.12 \mathrm{pg}$ [60]), and Gobionotothen (Gobionotothen gibberifrons, $0.98 \mathrm{pg}$ [71]). While there is no available genome size data for the sister groups of Nototheniidae (Bovichthidae, Eleginopsidae or Pseudaphritidae), or for the most recently proposed sister group of Notothenioidei, Percophidae [72], the genome sizes of other families phylogenetically close to the suborder Notothenioidei like Percidae (P. flavescens, 0.92 pg, P. fluviatilis, 0.90 pg, Percina caprodes, 1.06 pg, Sander lucioperca, 1.14 pg, Sander vitreus, 1.06 pg) [60, 73], or Serranidae (1.09 pg mean genome size, 0.17 s.d) [74] also range between 0.90 and 1.23 pg. This suggests that a $C$ value of $1-1.20 \mathrm{pg}$ could be the ancestral state, conserved throughout the Trematomus radiation. Therefore, karyotype diversity within the genus

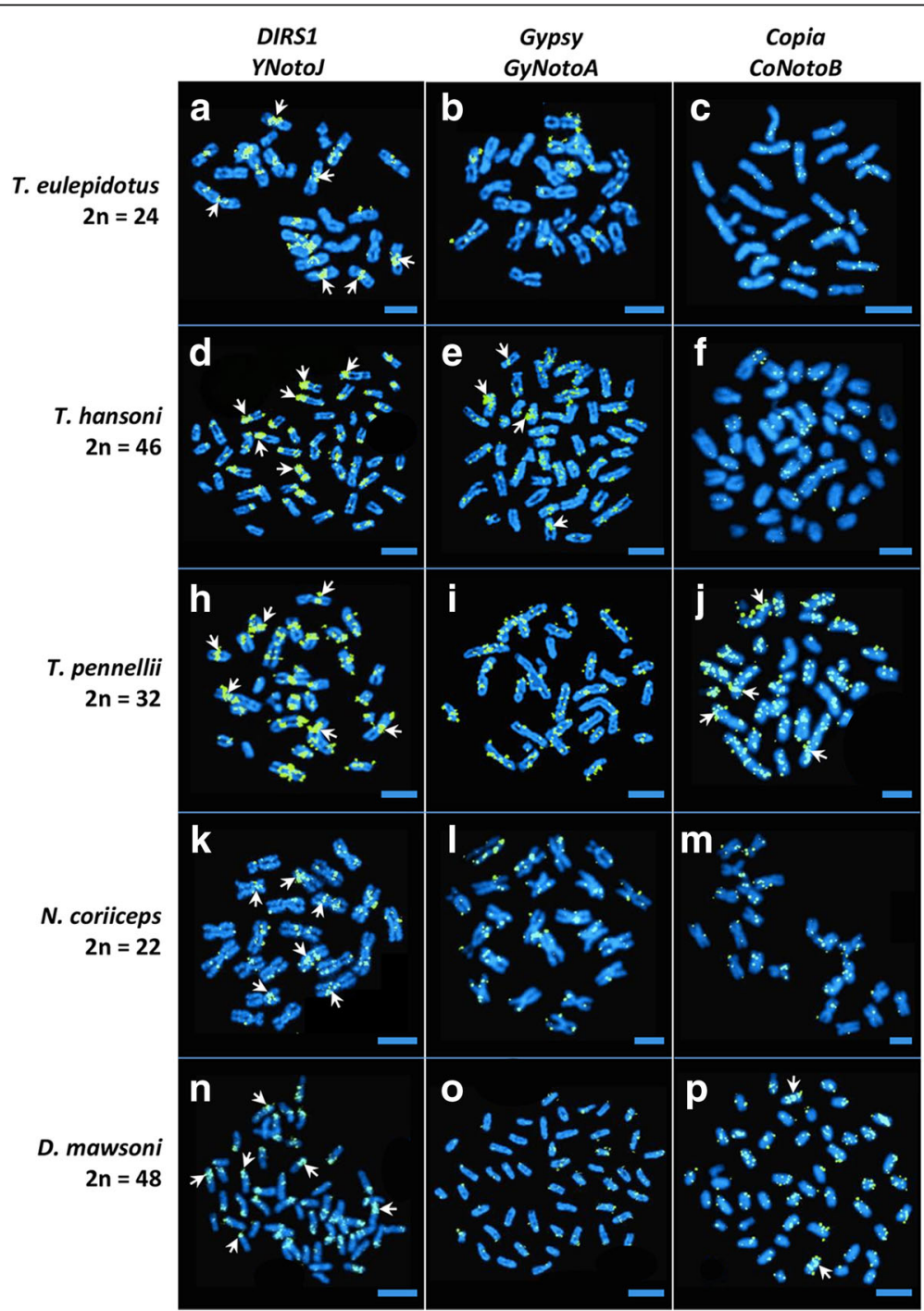

Fig. 4 Mapping of TEs on the chromosomes of five nototheniid species by FISH. Each probe was labeled with biotin and bound probe was detected with incubation with Avidin-FITC (fluorescein, greenish spots). (Probe characteristics are indicated in Additional file 6). Chromosomal DNA was counterstained with DAPI. One family of each retrotransposon superfamily is represented in this figure: YNotoJ for DIRSI, GyNotoA for Gypsy and CoNotoB for Copia elements. (see Additional files 7 and 8 for FISH mapping with the second family of DIRS1 (YnotoR) and Gypsy (GyNotoE)). Examples of TE distribution patterns for type 1: $\mathbf{d}$, $\mathbf{h}$; type $2: \mathbf{c}, \mathbf{i}$; type $1+2: \mathbf{e}, \mathbf{j}$, $\mathbf{p}$. White arrows point examples of TE accumulations. Scale bars: $10 \mu \mathrm{m}$ 
Trematomus occurred without much variation in the amount of DNA per genome. Rearrangements involving changes in Trematomus chromosome numbers and formulae are structural modifications like tandem or Robertsonian centric fusions $(2 \mathrm{n}=24$ in T. eulepidotus, $2 \mathrm{n}=32$ in T. pennellii and $2 \mathrm{n}=45-46$ in T. hansoni, $T$. borchgrevinki and T. newnesi) or fissions ( $2 \mathrm{n}=57-58$ in $T$. nicolai) and maybe inversions. However, inversions could not be detected using FISH or classical chromosome banding tools $[54,55]$.

Genome size stability is not observed in all nototheniid species. We also measured the $\mathrm{C}$-values of some nototheniid species from the sub-families Channichtyinae, Gynmodraconinae and Bathydraconinae, phylogenetically closely related to each other, but further from the Trematominae. Although few species have been measured yet, they display higher $\mathrm{C}$-values: $1.72 \mathrm{pg}$ for Chionodraco hamatus, $1.54 \mathrm{pg}$ for Gymnodraco acuticeps, and 1.34 pg for Parachaenichtys charcoti. This noticeable genome size augmentation could be explained by massive transpositions, segmental or genome duplication that could have happened during diversification of these groups $[2,18,71]$.
Did TE mobilization favor chromosomal diversification during the Trematomus radiation?

To evaluate the representation of some DIRS1, Gypsy, and Copia families in nototheniid genomes in the absence of a well-assembled genome available to run exhaustive computational analyses, we tried to estimate their copy number using $\mathrm{qPCR}$ approaches relative to two single copy gene standards. Despite the repeated nature of the TE sequences, this approach has already been used to estimate TE copy number on genomic DNA $[62,75,76]$. The same TE families quantified by qPCR were also mapped on nototheniid chromosomes using FISH. Even if FISH is not precise enough to estimate accurate TE copy numbers, we could estimate their relative number by the intensity of signals (Figs. 4, 5, Additional files 7, 8). There is a consistency between the two approaches that is generalizable to the five nototheniids studied (numerous hot spots and high copy number, few interspersed spots and low number of copies) (Table 4, Fig. 5, Additional file 7). In at least a few cases, there is probably a tendency for the qPCR to underestimate the real copy number, as based on their intensity most FISH signals correspond to multiple copies. This is

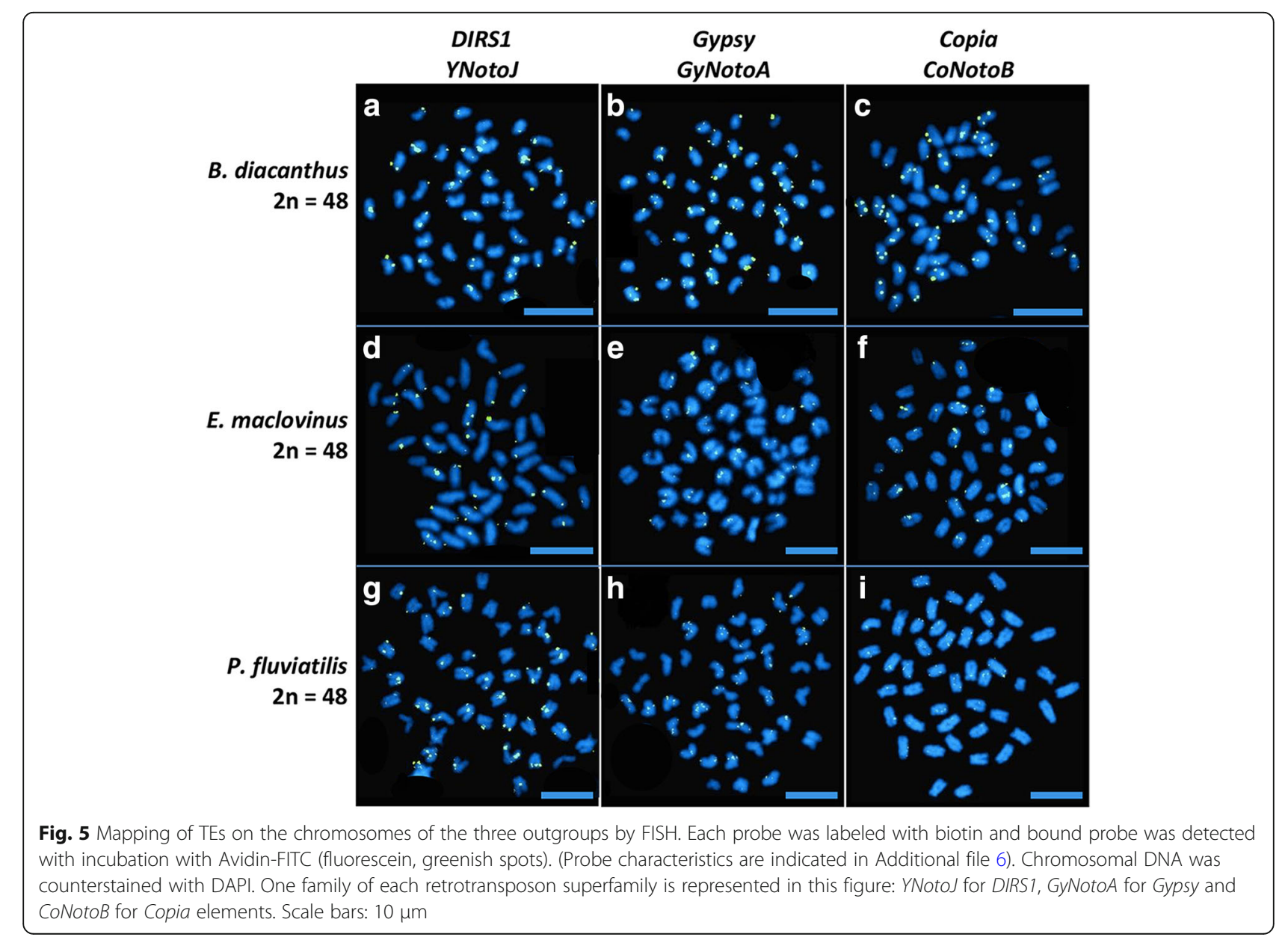


particularly obvious for the $\mathrm{Hydra}(\mathrm{CoNotoB})$ probe as there are multiple spots (certainly more than the estimated 10 copies) present in all chromosomes of N. coriiceps and D. mawsoni (Fig. 4, Table 4). The regions amplified by qPCR are only a portion of the TE sequence used as probe for FISH; the signals are therefore not totally comparable. Whole or partial genome sequencing would be needed to get more precise estimations of relative weights of TE families in those genomes and their respective true copy numbers.

The copy number estimated for DIRS1 elements is higher than for Gypsy and Copia retrotransposons in all five genomes quantified. It cannot, however, be excluded that the quantification of Gypsy elements is more biased by unequal amplification because of their higher family diversity (we quantified two of the four identified DIRS1 families vs two of the nine identified Gypsy families). This tendency of DIRS1 prevalence is even more pronounced for the three Trematomus species studied, $T$. eulepidotus, T. hansoni and T. pennellii. The predominance of DIRS1 copies over Gypsy and Copia copies is contrary to the strong prevalence of Gypsy previously reported in the Takifugu genome (10 putative copies of DIRS, 35 copies of BEL/Pao, 50 copies of Copia and 2500 copies of Gypsy identified) [64], in the zebrafish genome (46,806 copies of DIRS, 4585 copies of BEL/Pao, 10,293 copies of Copia and 56,138 copies of Gypsy identified) [25], and in two nototheniid genomes based on partial sequencing of a BAC library (for $N$. coriiceps, 17 copies of DIRS, 1 copy of Copia and 49 copies of Gypsy identified, for $C$. aceratus, 46 copies of DIRS, 25 copies of Copia and 156 copies of Gypsy identified, no BEL/Pao identified in both cases) $[60,71]$. The DIRS1 prevalence in Trematomus and other High Antarctic species investigated is consistent with the observed FISH signals (Fig. 4). As it has been proposed in several studies, strong multiplication of retrotransposons could have happened during chromosomal diversification accompanying speciation events $[1,13,18,58,59,77-80]$. The bursts of retrotransposons could therefore have occurred during the radiation of Trematomus and other AFGP-bearing nototheniid relatives (Chaniichthyinae, Artedidraconinae).

The possible implication of massive TE mobilization in the observed Trematomus and nototheniid species chromosomal rearrangements is dependent on their location on the chromosomes. We noticed a major difference of DIRS1 insertion patterns compared to those of Gypsy or Copia elements. Gypsy and Copia have numerous and scattered interstitial hybridization spots on chromosomes with no clear regions of accumulation, a pattern comparable to those previously reported for $T c 1$ like DNA transposons [58] and for Rex-like non-LTR retrotransposons [59] with mappings on nototheniids chromosomes (including T. bernacchii, T. hansoni, T. newnesi and T. pennellii). In striking contrast, DIRS1 elements accumulate in hot spots of insertion mostly located in centromeric and pericentromeric regions (Fig. 4) for the several nototheniid radiations studied, including in Chionodraco hamatus (sub-family Channichthyinae). In the biggest chromosome pair of $T$. pennelli, which certainly arose from two fusions (C. Ozouf-Costaz, unpublished data), there is an intercalary band of DIRS1 in the long arm in addition to the pericentromeric hot spot. This pattern of insertion is reminiscent of the one highlighted by Ozouf-Costaz et al. with $\operatorname{Rex} 3$ retrotransposon on the $\mathrm{Y}$ chromosome (originating from a tandem fusion between one $\mathrm{X} 1$ and one X2 autosome) of C. hamatus [59]. The intercalary band observed in the long arm of this $\mathrm{Y}$ chromosome suggest Rex3 involvement in the tandem fusion (telomere-centromere) between the two $\mathrm{X} 1$ and $\mathrm{X} 2$ autosomes this chromosome originates from $[53,56]$.

DIRS1 are not structured like LTR retrotransposons and this specificity may be linked with it particular origin. Discovered in the slim mold Dictyostelium discoideum [23], DIRS1 might have arisen from the combination of a crypton-like transposon using tyrosine recombinase (YR) to cut and rejoin the recombining DNA molecules and the RT/RH part of a pre-existing Gypsy LTR retrotransposon [22]. Various molecular mechanisms for DIRS1 insertion in targeted sites (by integration, recombination) have been proposed but remain to be experimentally demonstrated $[23,24,26]$. A specific insertion mode was deduced [81] from this singular molecular structure: via a double-stranded circular pre-integrative DNA intermediate, catalyzed by the YR. This explains the absence of Target Site Duplication (TSD) following transposition [78, 82]. This is reminiscent of bacterial processes and could lead to ectopic recombination [2, 7] and thus, to rearrangements. Hot spots of insertion for DNA transposons (Tc1-like) and retrotransposons (Rex-like) have already been described a number of times in the literature for other teleost fish groups [58, 65, 80, 83, 84]. DIRS1 clustering in hot spots of integration is probably not random. Many DIRS1 elements appear to have preferential target site selection and insert into their pre-existing copies in Danio rerio $[85,86]$. This process, also called "homing", is usually reported for class II TEs, such as the Drosophila P element [87] and, to our knowledge, has been rarely reported for retrotransposons. Like the other TEs localized in teleost fish chromosomes [58, 65, 80, 83, 84], DIRS1 inserts in " sheltered " heterochromatic regions [31, 80, 84, 88, 89]. Such locations in regions less affected by selection and with lower recombination rates might protect the TEs [90]. It might also has been selected as a way to protect and structure genomes, ensuring a kind of self-control of their mobilization $[1,20,65,83]$. 
A breakdown of epigenetic control mechanisms [2, 3, 36] could have favored DIRS1, Gypsy, and Copia activation, both in Trematomus species and other AFGP-bearing nototheniid relatives. According to recent time-calibrated molecular phylogeny analyses [45, 51], the Trematomus species diversification occurred in the middle - late Miocene (- 17 to $-5 \mathrm{My}$ ), corresponding to a cooling of shallow Antarctic shelf waters, followed by rapid switches between glacial and interglacial conditions [42-44, 91]. This could have led to transpositional waves through genomes $[11,21,62]$ possibly linked to species diversification $[2,3]$. On the contrary, B. diacanthus, E. maclovinus, P. fluviatilis (non AFGP-bearing species chosen as outgroups) were not exposed to series of environmental changes with cooling at sub-zero temperatures [42, 43], and do not reveal any regions of TE accumulation on their chromosomes for the studied TEs (Fig. 5). TE hot spots were not detected in Bovichtidae (including one species from the subantarctic Southern Ocean), or in the two temperate species from the families Eleginopsidae and Percidae (including a few species that originated in South America, Southern Australia/Tasmania and New-Zealand) [70]. Their karyotypes $(2 \mathrm{n}=48$, all acrocentric chromosomes [92-94]) are very stable across species [92, 95], suggesting few structural chromosomal rearrangements.

\section{Conclusions}

Transposable elements constitute key points to explore and understand genome evolution, especially in the recent divergence of Antarctic Trematomus species. While our TE exploration is wider than in previous studies, we cannot yet conclude the lack of detection of a given TE or family in a genome means they are absent. Targeted amplicon shotgun sequencing and untargeted genome sequencing are needed for more exhaustive exploration of TE populations and diversity.

No bursts linked with TE multiplication and accumulation on chromosomes were detected on the three temperate and subantarctic outgroups without AFGPs. On the contrary, exposure to strong environmental changes with cooling at sub-zero temperatures and series of glaciation and deglaciation cycles could have led to massive mobilization of retrotransposons (epigenetic deregulations), observed within Trematomus and other nototheniid genomes. A predominance of DIRS1 (probably several hundred of copies) in hot spots of insertion suggests they could have facilitated repeated and localized DNA double strand breaks on centromeric and pericentromeric regions. Then, the cellular repair mechanisms, close to recombination processes, might have favored tandem or centric fusions and boosted other genomic changes $[35,96]$. Chromosomal rearrangements reinforce reproductive isolation between distinct populations and drive vertebrate lineage diversification. They may have accompanied the Trematomus radiation.

Like the repeated independent emergences of the male Y-chromosome from centric fusions or tandem translocations, the chromosomal rearrangements observed in Trematomus species, and more generally in Nototheniidae, probably occurred independently as the result of convergent events. However, precise reconstruction of the evolutionary history of Trematomus chromosomal diversification requires identifying the inter-specific homologies between chromosomes. In this group, these homologies are generally impossible to establish due to the resemblance between chromosomes when using karyotype approaches based on chromosome morphology or size, and on DAPI counterstaining. Since it is impossible to recognize the chromosomes by classical techniques like banding, the development of tools like chromosome painting or BAC-FISH in these species would help to ascertain these inter-specific homologies [4], permitting a more precise history of the genome reorganizations (evolutionary scenario) in this group, and their possible relation with the speciation events, to be established.

\section{Methods}

\section{Fish specimens}

Specimens of thirteen High Antarctic nototheniids (Trematomus eulepidotus, T. pennelli, T. borchgrevinki, T. hansoni, T. bernacchii, T. loennbergi, T. lepidorhinus, $T$. newnesi, T. scotti, T. nicolä, I. cyanobrancha, Notothenia coriiceps, and Dissostichus mawsoni) and of two SubAntarctic notothenioid outgroups (Bovichtus diacanthus, Eleginops maclovinus) were collected during groundfish survey programs sponsored by the IPEV (Institut Polaire français Paul-Emile Victor) and the NSF (U.S. National Science Foundation): the ICEFISH 2004 Cruise (International Collaborative Expedition to collect and study Fish Indigenous to Sub-antarctic Habitats, Atlantic sector of the Southern Ocean), ICOTA (Icthyologie côtière en Terre Adélie, 1996-2008, Adelie Land), CEAMARC (Collaborative East Antarctic Marine Census for the Census of Antarctic Marine Life; 2007-2008, Eastern Antarctica, north of Adélie Land and George V Land), POKER (POissons de KERguelen, 2006, 2010 and 2013, shelf of Kerguelen-Heard islands) and REVOLTA (Ressources Ecologiques et Valorisation par un Observatoire à Long terme en Terre Adélie, 2010-2014, Adelie Land). Specimens of Perca fluviatilis were obtained in 2010 in Eaucourt (Somme, FRANCE) and are part of the MNHN collection. Tissue samples, chromosomal preparations and blood cells are referenced in Additional file 9. We used the nomenclature and classification of the SCAR atlas [70]. 


\section{Sample collection and preparation}

\section{Blood samples for flow cytometry}

Fish were anesthetized with MS 222 before sampling blood (minimum $0.5 \mathrm{ml}$ ) by caudal venipuncture using heparinized syringes. Whole blood was diluted 1:10 with PBS, $50 \mu \mathrm{l}$ aliquots of each blood sample were distributed dropwise to Eppendorf tubes containing $1 \mathrm{ml}$ of $70 \%$ ice cold ethanol, and the tubes were stored at $-20^{\circ} \mathrm{C}$.

\section{Tissues for DNA analyses}

Muscle samples or fin clips for DNA analyses were stored in $85 \%$ ethanol at $-20^{\circ} \mathrm{C}$. DNA was prepared following the protocol of Winnepenninckx et al. [97].

\section{Chromosome preparations}

Mitotic chromosome preparations were obtained from primary cell cultures of pronephric kidney or spleen according to Rey et al. [98]. Briefly, a suspension of cephalic kidney and/or spleen cells was prepared and cultured in L-15 Leibovitz culture medium without bicarbonate and supplemented with L-glutamine, fetal calf serum, lectins (concanavalin $\mathrm{A}$ and pokeweed mitogen) and antibiotics for periods up to one week at $0^{\circ}$ to $2{ }^{\circ} \mathrm{C}$. Colchicine was added $6 \mathrm{~h}$ prior to harvesting cells. This was followed by a hypotonic treatment $\left(1 \mathrm{~h}\right.$ at $\left.2{ }^{\circ} \mathrm{C}\right)$ and conventional steps of fixation. Fixed cell suspensions were preserved as aliquots of $15 \mathrm{ml}$ at $-20{ }^{\circ} \mathrm{C}$. Prior to use, the suspensions were thawed and centrifuged at $1500 \mathrm{rpm}$ (Eppendorf 5430 microcentrifuge) for $10 \mathrm{~min}$ at $4{ }^{\circ} \mathrm{C}$. After decanting the supernatant, the cell pellet was resuspended in $0.8-1 \mathrm{ml}$ of fresh fixative, and cells were spread onto Superfrost slides (pre-cleaned with absolute ethanol containing $1 \%$ of $1 \mathrm{~N} \mathrm{HCl}$ ). Slides were stored at $-20{ }^{\circ} \mathrm{C}$ until the FISH step.

Additional file 9 summarizes the blood samples, tissue samples, and chromosomal preparations used in this study.

\section{Retrotransposon amplification and fragment assembly} Amplification of retrotransposons using degenerate primers Retrostransposons were amplified from the genomes of all Trematomus species, with the exception of T. tokar$e v i$, and from two nototheniid sister species, $N$. coriiceps and D. mawsoni (Additional file 9). Rather than pursue full-length elements ( 5 to $10 \mathrm{~kb}$ ), we focused on their pol regions, as they include conserved domains and have a fundamental function in transposition. We amplified the retrotransposon pol fragments by PCR using degenerate oligonucleotide primer pairs designed for conserved protein motifs of the Reverse Transcriptase/ RNAseH (RT/RH) domains (Additional file 10). For Gypsy retrotransposons, the GD1b/GD2b primer pair overlaps the PFLG/DASXXGW motifs. CD1 had been designed to amplify Copia elements when used with $\mathrm{CD} 2$, as previously employed for the galatheid squat lobsters [99], but in nototheniid fishes, we found that it amplified the Gypsy Integrase gene, serving as both forward and reverse primer. For Copia elements, two primer pairs were used (CD3/CD4, CD5/CD6), which correspond to the DYCYR/DNQG and VDP/QLAD motifs, respectively. For DIRS1 retrotransposons, we used the DD10/DD11 pair, which encode the DlkdAY/ YafPPf motifs.

PCR was performed using 50 ng of genomic DNA, $2.5 \mathrm{U}$ of Taq DNA polymerase (Promega) and $50 \mathrm{pmol}$ of each degenerate primer in a final volume of $25 \mu \mathrm{L}$ for 35 cycles (94 ${ }^{\circ} \mathrm{C}$ for $45 \mathrm{~s}, 50.2{ }^{\circ} \mathrm{C}$ for $1 \mathrm{~min}$ and $72{ }^{\circ} \mathrm{C}$ for $1 \mathrm{~min}$ ). PCR products were visualized on $1 \%$ agarose gels. Fragments of the expected molecular weights were excised, purified with the Nucleospin Extraction kit (Macherey_ Nagel), and cloned into the pGEM-T vector according to the supplier's recommendations (Promega, Madison, WI, USA). Cloned fragments were sequenced in both directions (http://www.gatc-biotech.com).

\section{TE walking}

Optimal DNA fragment sizes for classification of retrotransposons and for use as FISH probes, in our experience, range between 1.0 and $1.5 \mathrm{~kb}$. The initial Gypsy amplicons $(0.7 \mathrm{~kb})$, in particular, did not meet this standard (Additional file 10). Therefore, we used "TE Walking" [21], anchored by specific primers designed from the original sequences and the GD4 degenerate primer (overlaps the YLDD motif), to extend the Gypsy fragments (Additional files 10 and 11). Copia and DIRS1 elements were extended in similar fashion. Each new sequence was manually validated as an extension of the original fragment using a minimum overlap of 50 bp between the two sequences and a minimum DNA identity of $95 \%$. Final retrotransposon sequences were assembled from their fragments using the Cap contig assembly program included in BioEdit v7.2.5 [100]. We then designed specific primer pairs that we used to amplify the desired pol fragments (Additional file 11). We obtained DNA cloned fragments from 1.0 to $1.5 \mathrm{~kb}$ size, depending on the TE element. Consensus sequences were deposited in BankIt (BankIt2016770: MF142597-MF142757). These larger DNA fragments were used for classification of retrotransposons and as FISH probes.

\section{Retrotransposon classification, clustering, and phylogenetic analyses Classification and clustering of retrotransposon families} Nototheniid TEs were assigned to a specific retrotransposon superfamily using BLASTX analyses [101] of a custom in-house TE database (2.2.28 + blastpackage), the NCBI protein database, and the $N$. coriiceps genome [102]. DIRS1, Gypsy, or Copia sequences were clustered using BLASTClust toolkit v2.2.26 [103]. A cluster of 
sequences was considered a separate family if its highest intra-group divergence was lower than the divergence between all putative families, without overlap of the two distributions [21].

The criteria for inclusion of a fragment in a cluster (i.e., family) were $\geq 30 \%$ sequence coverage and $\geq 80 \%$ sequence identity. We adopted the following nomenclature: YNotoJ, $V, R$, and $B$ are the four identified families of DIRS1; GyNotoA, B, D, E, F, H, I, J, and $R T$, the nine identified families of Gypsy; CoNotoA and $\operatorname{CoNotoB}$, the two identified families of Copia. Nucleic acid sequence identity matrices were calculated after alignment of sequences by MAFFT v7 [104] and gap removal using BioEdit v7.2.5.

\section{Phylogenetic analysis of nototheniid retrotransposons}

The sequences of the nototheniid DIRS1, Gypsy, and Copia families were highly conserved across the genera examined. To establish their phylogenetic relationships with respect to TEs from other eukaryotes, we first generated a majority rule nucleotidic consensus for each family of DIRS1, Gypsy and Copia TEs using Geneious v9.0.2 (http://www.geneious.com, [105]), then translated them to generate corresponding amino acid sequences. For DIRS1 elements, the four nototheniid consensus sequences were added to a dataset of DIRS1 [27] that span 96 amino acid sequences of the RT/RH region and represent numerous eukaryote taxa (including Fungi, Crustaceans, Nematodes). Two phylogenetic analyses of the nine Gypsy consensus sequences were performed, the first covering the RT/RH region (110 amino acids) and the second the INT region (99 amino acids). Nototheniid consensus sequences were added to the Gypsy sequence compilation [67]. Similarly, CoNotoA and $\operatorname{CoNoto} B$ sequences that span the RT/RH region were compared to a Copia dataset [67]. The final datasets contained 282 informative sites for DIRS1, 167 for Gypsy RT/RH, 153 for Gypsy INT and 220 for Copia.

Multisequence alignments were performed with MAFFT v7 and ambiguously aligned sites were removed using Gblocks [106]. Neighbor-joining (NJ) phylogenies were obtained using MEGA 5.2.2 [107]. The best-fit model was selected with Topali v2, implemented using PhyML [108] and the JTT model [109] with gamma distribution. Maximum Likelihood (ML) phylogenetic reconstructions were obtained using RAxML [110] and the evolution model PROTGAMMALG. Support for individual clusters was evaluated using non-parametric bootstrapping [111] and 1000 bootstrap replicates. Nodes under $60 \%$ were collapsed.

We selected outgroups for each reconstruction according to previously published retroelement relationships $[17,23,30,86]$. Due to the proximity (sequence identity) of their RT/RH domains, we chose the DIRS1 outgroup for the Gypsy reconstruction and reciprocally, Gypsy as outgroup for the DIRS1 and Copia analyses. Because DIRS1 elements do not encode an Integrase (but a tYrosine Recombinase), Copia (GalEa) sequences were used as root for the Gypsy analysis based on Integrase consensus fragments.

\section{FISH}

\section{TE probe preparation}

DIRS1, Gypsy and Copia clones from T. bernacchii, T. pennellii and $N$. coriiceps greater than $1 \mathrm{~kb}$ in length were used as probes for FISH experiments (Additional file 6). TE probes were biotinylated by nick translation according to the manufacturer's instructions (Roche Diagnostics). For the double FISH mapping, we used probes in which fluorochromes were directly incorporated during the labeling step; Fluorescein for YNotoJ, and Rhodamine for YNotoR, using the ULS PlatiniumBright Nucleic Acid Labeling Kit (Leica Biosystems). Each probe was dissolved at a final concentration of $20 \mathrm{ng} / \mu \mathrm{l}$ in high stringency hybridization buffer [65\% formamide, $2 \times \mathrm{SSC}, 10 \%$ dextran sulfate $(\mathrm{pH} 7)]$.

\section{FISH with TE probes}

To ensure signal specificity for the three TE superfamilies, FISH was performed on chromosome preparations under high stringency conditions. Chromosome preparations were obtained from eight fish species, including five nototheniids (T. pennelli, T. hansoni, T. eulepidotus, $N$. coriiceps, $D$. mawsoni) and the three outgroup species (B. diacanthus, E. maclovinus, and P. fluviatilis). Biotinylated TE probes, denatured by heating at $85{ }^{\circ} \mathrm{C}$ for 5 min, were applied to freshly thawed chromosome preparations, which were then incubated at $72{ }^{\circ} \mathrm{C}$ for ten seconds to one minute. Bound probes were detected using Avidin-FITC (fluorescein) according to the protocol of Bonillo et al. [112], which is optimized for repetitive sequences and multi-copy genes. Hybridization parameters were adjusted to each chromosome preparation: we pre-incubated the slides at $37{ }^{\circ} \mathrm{C}$ to make chromosomes more resistant to denaturation, determined specific chromosome denaturation times for each specimen and tested several probe concentrations to select the one most adapted to our chromosomal material $[113,114]$.

\section{Image acquisition and karyotyping}

FISH signals were detected using a Zeiss Axioplan microscope equipped with a cooled CCD camera (Coolsnap Photometrics) and an XCite LED fluorescence light source. Karyotypes were processed using CytoVision 3.93.2/ Genus FISH-imaging software for animal chromosomes 
(Leica Microsystems). Ten to forty metaphase spreads/species for each probe were examined.

\section{Quantification \\ Genome size determination}

The flow cytometry procedure was based on Detrich et al. [60]. $500 \mu \mathrm{l}$ of each sample was washed twice by centrifugation (Eppendorf 5430 microcentrifuge, $1500 \mathrm{rpm}$, $4{ }^{\circ} \mathrm{C}, 5 \mathrm{~min}$ ), first in $0.01 \mathrm{M} \mathrm{PBS}$ followed by $0.01 \mathrm{M}$ PBS containing RNAse $(10 \mu \mathrm{g} / \mathrm{ml}$, Miltenyi Biotec) and propidium iodide (PI; $50 \mu \mathrm{g} / \mathrm{ml}$, Sigma Aldrich). Flow cytometry measurements were performed using a MACSQuant 10 flow cytometer. Unstained cells were used to determine autofluorescence thresholds and to calibrate the acquisition mode. Rainbow trout (Oncorhynchus mykiss) blood was collected at the Institut National de la Recherche Agronomique (INRA), Jouyen-Josas ("synthetic INRA" strain, 2015). This rainbow trout provides our genome size reference, as it has been repeatedly estimated by flow cytometry with a mean calculated C-value of $2.695 \mathrm{pg}$ (see also Volff et al. [13]: $2600 \mathrm{Mbp}$ with $978 \mathrm{Mbp}=1 \mathrm{pg}$ ). We systematically started each run with triplicate measurements of the reference rainbow trout, followed by $N$. coriiceps and $T$. bernachii prior to data acquisition for the other nototheniid samples (Additional file 1). At least 10,000 cells were measured per sample and each experiment was replicated 3X. Fluorescence intensities, which were analyzed using Flowjo v10 software, reflect PI intercalation into DNA and are directly proportional to genome size. The genome sizes were calculated by comparing the mean of fluorescence intensity (MFI) of each sample to the MFI of our reference.

\section{TE copy number determination by quantitative PCR (qPCR)}

qPCR reactions were performed in a CFX96 Touch Real-time PCR Detection System (Bio-Rad). Specific primer pairs were designed with Oligo Analyzer v1.2, 1) to amplify 450 - $500 \mathrm{bp}$ fragments overlapping the $\mathrm{RT} / \mathrm{RH}$ conserved region of DIRS1, Gypsy and Copia TEs, and 2) to amplify fragments of similar size from the single copy RAG1 and Rhodopsin genes (Additional file 12). The best practice recommendations of Bustin et al. [115] were followed for sample preparation. PCR amplifications were performed in a final volume of $20 \mu \mathrm{l}$ containing $4 \mu \mathrm{l}$ of template DNA, $10 \mu \mathrm{mol}$ of each primer, $10 \mu \mathrm{l}$ of Sso Advanced Universal SYBR Green Supermix (Bio$\mathrm{Rad})$, and $4 \mu \mathrm{l}$ of DNAse free water. The PCR thermal cycling protocol began with polymerase activation and DNA denaturation at $98{ }^{\circ} \mathrm{C}$ for $4 \mathrm{~min}$, followed by $40 \mathrm{cy}-$ cles with denaturation for $15 \mathrm{~s}$ at $98{ }^{\circ} \mathrm{C}$ and annealing/ extension for $1.5 \mathrm{~min}$ at $62{ }^{\circ} \mathrm{C}$. After amplification, melting curve analyses were performed between 65 and $95{ }^{\circ} \mathrm{C}$ to determine amplification product specificity, with the temperature increasing of $0.1{ }^{\circ} \mathrm{C} / \mathrm{s}$. SYBR Green fluorescence was measured during the annealing/extension step. All samples were analyzed in triplicate with negative controls (different combinations: without DNA and primers, with DNA but without primers and with primers but without DNA).

For DIRS1 elements, we created a primer pair to quantify simultaneously both the YNotoR and YNotoB families due to their high similarity in the $\mathrm{RT} / \mathrm{RH}$ region (Additional file 12). Standard curves were generated for RAG1 and Rhodopsin in each run. We performed qPCR for all fragments (RAG1, Rhodopsin, YNotoJ, YNotoV, YNotoRB, GyNotoA, GyNotoE and CoNotoB) for five species: T. pennellii, T. hansoni, T. eulepidotus, $N$. coriiceps, and D. mawsoni. PCR products were systematically checked by sequencing to verify primer specificity (Genewiz). Four to five tenfold dilution standards were prepared fresh each time, ranging from 1 to $1 \times 10^{-4} \mathrm{ng} / \mu \mathrm{l}$. For both single copy gene standards, at least four dilutions in triplicate were obtained and plotted against Ct values. We estimated copy numbers of DIRS1, Gypsy and Copia family relative to both single copy (RAG1 on the one hand, and Rhodopsin on the other hand) calibration measurements using Bio-Rad CFX Manager v3.1, by comparison of their respective $C(t)$ values, normalized to the DNA concentration initially present in the sample dilution. The slope of the standard curves was calculated and the amplification efficiency (E) was estimated as $\mathrm{E}=\left(10^{-1} / \mathrm{slope}\right)^{-1}$ for each amplicon and each dilution. We measured efficiencies for both standards (mean of $98.2 \pm 2.6 \%$ ), and for the whole TE families (mean of $97.8 \pm 2.1 \%)$. Tm of each studied amplicon was constant between runs (Additional file 12).

\section{Additional files}

Additional file 1: Repeatability of measurements for flow cytometry values determining genome sizes. Mean of C-values triplicate measurements (pg) per specimens and per species. (PDF $112 \mathrm{~kb}$ )

Additional file 2: Detection of identified TEs among Trematomus, $N$. coriiceps and D. mawsoni genomes. Distribution of DIRS1, Gypsy and Copia TEs identified in Trematomus and nototheniid sister species. (PDF $105 \mathrm{~kb})$

Additional file 3: NJ bootstrap consensus tree for DIRS1 based on the RT/RH amino acid sequences. Complement of Fig. 1. We positioned our four DIRS1 family consensus sequences (YNotoJ, $V, R, B$ ) in the context of a larger diverse dataset composed of well-described TE families from numerous eukaryote genomes. (PDF $223 \mathrm{~kb}$ )

Additional file 4: NJ bootstrap consensus tree for Gypsy based on the amino acid sequences of the RT/RH (a) and INT (b) regions. Complement of Fig. 2. We positioned our nine Gypsy TE family consensus sequences (GyNoto $A, B, D, E, F, H, I, J, R T$ ) in the context of a larger diverse dataset composed of well-described TE families from numerous eukaryote genomes. (PDF $309 \mathrm{~kb}$ )

Additional file 5: NJ bootstrap consensus tree for Copia based on the RT/RH amino acid sequences. Complement of Fig. 3. We positioned our two Copia TE family consensus sequences (CoNoto $A, B)$ in the context of 
a larger diverse dataset composed of well-described TE families from numerous eukaryote genomes. (PDF $176 \mathrm{~kb}$ )

Additional file 6: Summary of TEs probes for FISH. sum up (name, superfamily, family, species it comes from, kb size) of cloned sequences used as probes for Fluorescent in situ hybridization. (PDF 86 kb)

Additional file 7: Mapping of TEs on the chromosomes of five nototheniid species by FISH. FISH mapping of a second family of DIRS 1 (YNotoR) and Gypsy (GyNotoE) identified and largely distributed in nototheniid genomes. (PDF $256 \mathrm{~kb}$ )

Additional file 8: Double mapping of two DIRS1 family representatives on chromosomes of T. hansoni. Double FISH with two DIRS1 family representatives (YNotoJ, directly labeled with fluorescein, greenish spots, and YNotoR, directly labled with Rhodamine, red spot). They are presented on a same metaphase spread. Firstly, with signals of each DIRS1 family separated, and secondly superimposed. (PDF $278 \mathrm{~kb}$ )

Additional file 9: Taxonomic sampling for tissues, chromosomal suspensions and blood cells used in this study. For "Materials section". Sum up of all specimen samples used for this study per Family and per Genus. Species (sample type, field reference, voucher reference). (PDF $26 \mathrm{~kb})$

Additional file 10: Degenerated PCR primers used to amplify retroelements in nototheniid genomes. For "Methods section". Sum up of degenerated primers (primer sequence, motif overlapped, fragment size (pb)) used to amplify DIRS1, Gypsy and Copia retrotransposons in nototheniid genomes. Exploration and "TE walking". (PDF 212 kb)

Additional file 11: Specific PCR primers used to amplify retroelements in nototheniid genomes (complement of Additional file 10). for "Methods section". Complement of Additional file 10. Sum up of specific primers (primer sequence and fragment size (pb)) used to amplify DIRS1, Gypsy and Copia retrotransposons in nototheniid genomes. Specific amplifications. (PDF $176 \mathrm{~kb}$ )

Additional file 12: Specific qPCR primer pairs. For "Methods section". Sum up of specific primers (primer sequence, fragment size (bp), region of amplification, Tm of amplification $\left({ }^{\circ} \mathrm{C}\right)$ ) used to amplify single copy genes RAG1 and Rhodopsin, and DIRS1, Gypsy and Copia retrotransposons in nototheniid genomes for TE copy number quantification. (PDF $149 \mathrm{~kb}$ )

\section{Abbreviations}

(q)PCR: (quantitative) Polymerase chain reaction; AFGP: Antifreeze glycoprotein; BAC: Bacterial artificial chromosome; DAPI : 4',6-diamidino-2phenylindole; DIG : Digoxigenin; FISH: Fluorescent in situ hybridization ; FITC : Fluorescein isothiocyanate; ICR: Internal complementary region; INRA: Institut National de la Recherche Agronomique; ITR: Inversed terminal repeat; MFI: Mean on fluorescence intensity; MT: Methyltranferase; My: Million years; NJ: Neighbor joining; ORFs: Open reading frames; PBS: Phosphate buffered saline; RH: RNAseH; RT: Reverse transcriptase; SSC : Sodium chloridesodium citrate buffer; TEs: Transposable elements; TSD: Target site duplication; YR: Tyrosine recombinase

\section{Acknowledgments}

We are grateful to Dimitri Rigaudeau (INRA of Jouy en Josas, FRANCE) for the Rainbow Trout blood sampling. We thank the crews and participants involved in the capture of the samples and chromosome preparations in different sectors of Antarctica and particularly M. Hautecoeur, G. Lecointre, H. D'Hont, S. Pavoine, C. Loots, O. Rey, J. Lanshere, T. Nebout, E. Pisano and C. Cheng. We thank Eva Pisano for additional samples, providing chromosomes of T. eulepidotus (stock of cytogenetic preparations for polar fishes organized by the CNR of Genoa, PNRA POLICY project). We thank the "Service de Systématique Moléculaire" (SSM, UMS 2700, MNHN/CNRS) for granting access to its technical platform and help. We are grateful to Pedro Bausero for his precious help and advices regarding our qPCR quantification of TE copy numbers. We also thank the editor and anonymous reviewers for their helpful comments.

\section{Funding}

This work, chromosome collection and preparation received financial support from the Institut Polaire français Paul-Emile Victor (IPEV) and the U.S. National Science Foundation (NSF) (programs Icthyologie côtière en Terre
Adélie (ICOTA 1996-2008) and Ressources Ecologiques et Valorisation par un Observatoire à Long terme en Terre Adélie (REVOLTA 2010-2014)); of Collaborative East Antarctic Marine Census for the Census of Antarctic Marine Life (CAML-CEAMARC 2007-2008, IPY project no. 53) cruise on board the RV Aurora Australis; of International Collaborative Expedition to collect and study Fish Indigenous to Sub-antarctic Habitats, Atlantic sector of the Southern Ocean (ICEFISH 2004), on board the R.V. Nathaniel Palmer (granted by National Science Foundation grant OPP 01-32032), of POissons de KERguelen, shelf of Kerguelen-Heard islands (POKER 2006, 2010, 2013) on board the "Austral" trawler (supported by the French National Research Agency ANR, and Ministry of Agriculture and Fisheries). The Université Pierre et Marie Curie (UPMC), the Centre National de la Recherche Scientifique (CNRS), the Museum National d'Histoire Naturelle (MNHN) and the Australian Antarctic Division (AAD) provided financial supports. HWD was also supported by the U.S. National Science Foundation (NSF) grant PLR-1444167. This is contribution 365 from the Marine Science Center at Northeastern University.

\section{Availability of data and materials}

The datasets (TE sequences and genome sizes) supporting the conclusions of this article are available in the GenBank NCBI repository (Banklt 2,016,770, refs MF142597 to MF142757) and on the genome size database repositories.

\section{Authors' contributions}

Experiments were conceived, discussed and designed by DH, COC, AD, HWD and JA. The TE sequence dataset was generated with the kind help of PG and $L B$, and analyzed by DH and JA; FISH and $\mathrm{qPCR}$ experiments and analyses by JA, helped by LP, for flow cytometry experimental design, data acquisitions and analyses. The manuscript was prepared by JA and HWD. EB, $\mathrm{DH}, \mathrm{COC}, \mathrm{HWD}$ and $\mathrm{AD}$ made a critical revision of the manuscript and participated in helpful discussions. All authors read and approved the final manuscript.

\section{Authors' information}

2: LP is in charge of the cytometers from the imaging platform of Sorbonne Université, 75,252 Paris, cedex 05

\section{Ethics approval and consent to participate}

Ethical approval for all procedures was granted by the ethics committee of the Ministère de l'Environnement and the French Polar Research Institute (Institut Paul Emile Victor - IPEV), which approved all our fieldwork. The experiments complied with the Code of Ethics of Animal Experimentation in the Antarctic sector.

\section{Competing interests}

The authors declare that they have no competing interests.

\section{Publisher's Note}

Springer Nature remains neutral with regard to jurisdictional claims in published maps and institutional affiliations.

\section{Author details}

${ }^{1}$ Laboratoire Evolution Paris Seine, Sorbonne Université, Univ Antilles, CNRS Institut de Biologie Paris Seine (IBPS), F-75005 Paris, France. ${ }^{2}$ Plateforme d'Imagerie et Cytométrie en flux, Sorbonne Université, CNRS, - Institut de Biologie Paris-Seine (BDPS - IBPS), F-75005 Paris, France. ${ }^{3}$ Institut de Systématique, Evolution, Biodiversité (ISYEB), Museum National d'Histoire Naturelle, CNRS, Sorbonne Université, EPHE, 57, rue Cuvier, 75005 Paris, France. ${ }^{4}$ Institut Pasteur, Laboratoire Signalisation et Pathogénèse, UMR CNRS 3691, Bâtiment DARRE, 25-28 rue du Dr Roux, 75015 Paris, France.

${ }^{5}$ Department of Marine and Environmental Sciences, Marine Science Center, Northeastern University, Nahant, MA 01908, USA.

Received: 31 October 2017 Accepted: 23 April 2018

Published online: 09 May 2018

\section{References}

1. Böhne A, Brunet F, Galiana-Arnoux D, Schultheis C, Volff J-N. Transposable elements as drivers of genomic and biological diversity in vertebrates. Chromosom Res. 2008;16:203-15. 
2. Kraaijeveld K. Genome size and species diversification. Evol Biol. 2010;37:227-33.

3. Rebollo R, Horard B, Hubert B, Vieira C. Jumping genes and epigenetics: towards new species. Gene. 2010;454:1-7.

4. Ozouf-Costaz C, Pisano E, Thaeron C, Hureau J-C. Antarctic fish chromosome banding: significance for evolutionary studies. Cybium. 1997;21:399-409.

5. Garagna S, Marziliano N, Zuccotti M, Searle JB, Capanna E, Redi CA. Pericentromeric organization at the fusion point of mouse Robertsonian translocation chromosomes. Proc Natl Acad Sci. 2001;98:171-5.

6. Devos KM, Brown JK, Bennetzen JL. Genome size reduction through illegitimate recombination counteracts genome expansion in Arabidopsis. Genome Res. 2002;12:1075-9.

7. Bonnivard E, Higuet D. Fluidity of eukaryotic genomes. C R Biol. 2009;332:234-40.

8. Kehrer-Sawatzki H, Cooper DN. Understanding the recent evolution of the human genome: insights from human-chimpanzee genome comparisons. Hum Mutat. 2007;28:99-130

9. Raskina O, Barber JC, Nevo E, Belyayev A. Repetitive DNA and chromosomal rearrangements: speciation-related events in plant genomes. Cytogenet Genome Res. 2008;120:351-7.

10. Warren IA, Naville M, Chalopin D, Levin P, Berger CS, Galiana D, et al. Evolutionary impact of transposable elements on genomic diversity and lineage-specific innovation in vertebrates. Chromosom Res. 2015;23:505-31.

11. Mahé F. Phylogénie, éléments transposables et évolution de la taille des génomes chez les lupins [lnternet]. Université Rennes 1; 2009 [cited 2016 Jun 27]. Available from: https:/tel.archives-ouvertes.fr/tel-00494607/.

12. Ferreira IA, Poletto AB, Kocher TD, Mota-Velasco JC, Penman DJ, Martins C. Chromosome evolution in African cichlid fish: contributions from the physical mapping of repeated DNAs. Cytogenet Genome Res. 2010;129:314-22.

13. Volff J-N. Genome evolution and biodiversity in teleost fish. Heredity. 2005; 94:280-94.

14. Chénais B. Transposable elements in cancer and other human diseases. Curr Cancer Drug Targets. 2015;15:227-42.

15. Sela N, Kim E, Ast G. The role of transposable elements in the evolution of non-mammalian vertebrates and invertebrates. Genome Biol. 2010;11:1.

16. Wicker T, Sabot F, Hua-Van A, Bennetzen JL, Capy P, Chalhoub B, et al. A unified classification system for eukaryotic transposable elements. Nat Rev Genet. 2007:8:973-82.

17. Eickbush TH, Malik HS. Origins and evolution of retrotransposons. In: Craig NL, Lambowitz AM, Craigie R, Gellert M, editors. Mob DNA II [Internet]. American Society of Microbiology; 2002 [cited 2017 Jan 3]. p. 1111-44 Available from: http://www.asmscience.org/content/book/10.1128/ 9781555817954.chap49.

18. Kidwell MG. Transposable elements and the evolution of genome size in eukaryotes. Genetica. 2002;115:49-63.

19. Volff J-N, Bouneau L, Ozouf-Costaz C, Fisher C. Diversity of retrotransposable elements in compact pufferfish genomes. Trends Genet. 2003;19:674-8.

20. Hua-Van A, Le Rouzic A, Maisonhaute C, Capy P. Abundance, distribution and dynamics of retrotransposable elements and transposons: similarities and differences. Cytogenet Genome Res. 2005;110:426-40.

21. Piednoël M, Bonnivard E. DIRS1-like retrotransposons are widely distributed among Decapoda and are particularly present in hydrothermal vent organisms. BMC Evol Biol. 2009;9:86.

22. Poulter RT, Butler MI. Tyrosine recombinase retrotransposons and transposons. Microbiol Spectr. 2015;3:1-20. https://doi.org/10.1128/ microbiolspec.MDNA3-0036-2014.

23. Goodwin TJ, Poulter RT. The DIRS1 group of retrotransposons. Mol Biol Evol. 2001;18:2067-82.

24. Goodwin TJD. A new group of tyrosine recombinase-encoding retrotransposons. Mol Biol Evol. 2004;21:746-59.

25. Howe K, Clark MD, Torroja CF, Torrance J, Berthelot C, Muffato M, et al. The zebrafish reference genome sequence and its relationship to the human genome. Nature. 2013;496:498-503.

26. Poulter RT, Goodwin T. DIRS-1 and the other tyrosine recombinase retrotransposons. Cytogenet Genome Res. 2005;110:575-88.

27. Piednoël M, Gonçalves IR, Higuet D, Bonnivard E. Eukaryote DIRS1-like retrotransposons: an overview. BMC Genomics. 2011;12:1.

28. Wicker T, Keller B. Genome-wide comparative analysis of copia retrotransposons in Triticeae, rice, and Arabidopsis reveals conserved ancient evolutionary lineages and distinct dynamics of individual copia families. Genome Res. 2007;17:1072-81.

29. Wang H, Liu J-S. LTR retrotransposon landscape in Medicago truncatula: more rapid removal than in rice. BMC Genomics. 2008;9:382.
30. Rho M, Schaack S, Gao X, Kim S, Lynch M, Tang H. Research article LTR retroelements in the genome of Daphnia pulex. 2010. [cited 2017 Jan 3]. Available from: https://www.researchgate.net/publication/45148065_LTR_ retroelements_in_the_genome_of_Daphnia_pulex.

31. Biemont C, Vieira C. What transposable elements tell us about genome organization and evolution: the case of Drosophila. Cytogenet Genome Res. 2005;110:25-34

32. Symonová R, Majtánová Z, Sember A, Staaks GB, Bohlen J, Freyhof J, et al. Genome differentiation in a species pair of coregonine fishes: an extremely rapid speciation driven by stress-activated retrotransposons mediating extensive ribosomal DNA multiplications. BMC Evol Biol. 2013;13:42.

33. McClintock B. The significance of responses of the genome to challenge. Science. 1984:226:792-801.

34. Dion-Cote A-M, Renaut S, Normandeau E, Bernatchez L. RNA-seq reveals transcriptomic shock involving transposable elements reactivation in hybrids of young Lake whitefish species. Mol Biol Evol. 2014;31:1188-99.

35. Oliver KR, Greene WK. Transposable elements: powerful facilitators of evolution. BioEssays. 2009;31:703-14.

36. Mansour A. Epigenetic activation of genomic retrotransposons. J Cell Mol Biol. 2007;6:99-107.

37. Lim JK, Simmons MJ. Gross chromosome rearrangements mediated by transposable elements in Drosophila melanogaster. BioEssays. 1994;16:269-75.

38. Aulard $\mathrm{S}$, Vaudin $\mathrm{P}$, Ladevèze $\mathrm{V}$, Chaminade $\mathrm{N}$, Périquet $\mathrm{G}$, Lemeunier $\mathrm{F}$. Maintenance of a large pericentric inversion generated by the hobo transposable element in a transgenic line of Drosophila melanogaster. Heredity. 2004;92:151-5.

39. Ladevèze V, Chaminade N, Lemeunier F, Periquet G, Aulard S. General survey of hAT transposon superfamily with highlight on hobo element in Drosophila. Genetica. 2012;140:375-92.

40. Zhang J. Transposition of reversed ac element ends generates chromosome rearrangements in maize. Genetics. 2004;167:1929-37.

41. Pace JK, Feschotte $C$. The evolutionary history of human DNA transposons: evidence for intense activity in the primate lineage. Genome Res. 2007;17:422-32.

42. Kennett JP. Miocene paleoceanography and plankton evolution. Mesoz Cenozoic Oceans. 1986;15:119-22. Washington, D.C: K. J. Hsü.

43. Kennett J, Barker P. Latest cretaceous to Cenozoic climate and oceanographic development in the Weddell Sea: an ocean drilling perspective. Proc Ocean Drill Proj Sci Results. 1990;113:937-60.

44. Stott LD, Kennett JP, Shackleton NJ, Corfield RM. 48. The evolution of Antarctic surface waters during the PALEOGENE: inferences from the stable isotopic composition of planktonic foraminifers, ODP leg 1131. Proc Ocean Drill Proj Sci Results. 1990;113:849-63.

45. Near TJ, Dornburg A, Kuhn KL, Eastman JT, Pennington JN, Patarnello T, et al. Ancient climate change, antifreeze, and the evolutionary diversification of Antarctic fishes. Proc Natl Acad Sci. 2012;109:3434-9.

46. Eastman J. Fishes on the Antarctic continental shelf: evolution of a marine species flock? J Fish Biol. 2000;57:84-102.

47. Lecointre G, Améziane N, Boisselier M-C, Bonillo C, Busson F, Causse R, et al. Is the species flock concept operational? The Antarctic shelf case. RopertCoudert Y, editor. PLoS One. 2013;8:e68787.

48. Rutschmann S, Matschiner M, Damerau M, Muschick M, Lehmann MF, Hanel $R$, et al. Parallel ecological diversification in Antarctic notothenioid fishes as evidence for adaptive radiation: ECOLOGICAL DIVERSIFICATION IN NOTOTHENIOIDS. Mol Ecol. 2011;20:4707-21.

49. Lautrédou A-C, Hinsinger DD, Gallut C, Cheng C-HC, Berkani M, Ozouf-Costaz

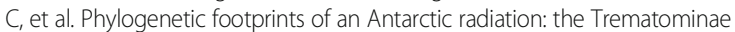
(Notothenioidei, Teleostei). Mol Phylogenet Evol. 2012;65:87-101.

50. Dettai A, Berkani M, Lautredou A-C, Couloux A, Lecointre G, OzoufCostaz C, et al. Tracking the elusive monophyly of nototheniid fishes (Teleostei) with multiple mitochondrial and nuclear markers. Mar Genomics. 2012;8:49-58.

51. Colombo M, Damerau M, Hanel R, Salzburger W, Matschiner M. Diversity and disparity through time in the adaptive radiation of Antarctic notothenioid fishes. J Evol Biol. 2015;28:376-94.

52. Ozouf-Costaz C, Hureau J-C, Beaunier M. Chromosome studies on fish of the suborder Notothenioidei collected in the Weddell Sea during EPOS 3 cruise. Cybium. 1991;15:271-89.

53. Ghigliotti L, Cheng CC-H, Ozouf-Costaz C, Vacchi M, Pisano E. Cytogenetic diversity of notothenioid fish from the Ross Sea: historical overview and updates. Hydrobiologia. 2015;761:373-96. 
54. Morescalchi A, Pisano E, Stanyon R, Morescalchi MA. Cytotaxonomy of antarctic teleosts of the Pagothenia/Trematomus complex (Nototheniidae, Perciformes). Polar Biol. 1992;12:553-8.

55. Pisano E, Ozouf-Costaz C. Chromosome change and the evolution in the Antarctic fish suborder Notothenioidei. Antarct Sci [Internet]. 2000 [cited 2017 Jan 2];12. Available from: http://www.journals.cambridge.org/abstract_ S0954102000000390

56. Pisano E, Cocca E, Mazzei F, Ghigliotti L, Di Prisco G, Detrich HW III, et al. Mapping of a-and $\beta$-globin genes on Antarctic fish chromosomes by fluorescence in-situ hybridization. Chromosom Res. 2003;11:633-40.

57. Molina WF, de Freitas Bacurau TO. Structural and numerical chromosome diversification in marine Perciformes (Priacanthidae and Gerreidae). Cytologia (Tokyo). 2006;71:237-42.

58. Capriglione T, Odierna G, Caputo V, Canapa A, Olmo E. Characterization of a Tc1-like transposon in the Antarctic ice-fish, Chionodraco hamatus. Gene 2002;295:193-198.

59. Ozouf-Costaz C, Brandt J, KöRting C, Pisano E, Bonillo C, Coutanceau J-P, et al. Genome dynamics and chromosomal localization of the non-LTR retrotransposons Rex1 and Rex3 in Antarctic fish. Antarct Sci. 2004;16:51-7.

60. Detrich HW, Stuart A, Schoenborn M, Parker SK, Methé BA, Amemiya CT. Genome enablement of the notothenioidei: genome size estimates from 11 species and BAC libraries from 2 representative taxa. J Exp Zoolog B Mol Dev Evol. 2010;314B:369-81.

61. Cocca E, lorio SD, Capriglione T. Identification of a novel helitron transposon in the genome of Antarctic fish. Mol Phylogenet Evol. 2011;58:439-46.

62. Chen S, Yu M, Chu X, Li W, Yin X, Chen L. Cold-induced retrotransposition of fish LINEs. J Genet Genomics. 2017:44:385-94.

63. Llorens C, Muñoz-Pomer A, Bernad L, Botella H, Moya A. Network dynamics of eukaryotic LTR retroelements beyond phylogenetic trees. Biol Direct. 2009;4:41.

64. Aparicio S, Chapman J, Stupka E, Putnam N, Chia J, Dehal P, et al. Wholegenome shotgun assembly and analysis of the genome of Fugu rubripes. Science. 2002;297:1301-10.

65. Valente GT, Mazzuchelli J, Ferreira IA, Poletto AB, Fantinatti BEA, Martins C. Cytogenetic mapping of the Retroelements \&lt;i\&gt:Rex1, Rex3\&lt;/i\&gt; and \&lt; i\&gt:Rex6\&lt;/i\&gt; among cichlid fish: new insights on the chromosomal distribution of transposable elements. Cytogenet Genome Res. 2011;133:34-42.

66. Radice AD, Bugaj B, Fitch DH, Emmons SW. Widespread occurrence of the Tc1 transposon family: Tc1-like transposons from teleost fish. Mol Gen Genet MGG. 1994;244:606-12.

67. Piednoël M, Donnart T, Esnault C, Graça P, Higuet D, Bonnivard E . LTRretrotransposons in $\mathrm{R}$. Exoculata and other crustaceans: the outstanding success of GalEa-like Copia elements. Kashkush K, editor. PLoS One. 2013:8:e57675.

68. Donnart T, Piednoël M, Higuet D, Bonnivard É. Filamentous ascomycete genomes provide insights into Copia retrotransposon diversity in fungi. BMC Genomics [Internet]. 2017 [cited 2018 Feb 19];18. Available from: http://bmcgenomics.biomedcentral.com/articles/10.1186/s12864-017-3795-2.

69. Lautredou A-C, Bonillo C, Denys G, Cruaud C, Ozouf-Costaz C, Lecointre G, et al. Molecular taxonomy and identification within the Antarctic genus Trematomus (Notothenioidei, Teleostei): how valuable is barcoding with COl? Polar Sci. 2010;4:333-52

70. Duhamel G, Hulley P, Causse R, Koubbi P, Vacchi M, Pruvost $P$, et al. Biogegographic atlas of the Southern Ocean. De Broyer C, Koubbi P, Griffiths HJ, Raymond B, Udekem d'Acoz C. Cambridge: Scientific Committee on Antarctic Research: 2014. p. 328-52.

71. Detrich HW, Amemiya CT. Antarctic Notothenioid fishes: genomic resources and strategies for analyzing an adaptive radiation. Integr Comp Biol. 2010; 50:1009-17.

72. Near TJ, Dornburg A, Harrington RC, Oliveira C, Pietsch TW, Thacker CE, et al. Identification of the notothenioid sister lineage illuminates the biogeographic history of an Antarctic adaptive radiation. BMC Evol Biol [Internet]. 2015 [cited 2016 Jun 27];15. Available from: http://www. biomedcentral.com/1471-2148/15/109.

73. Hardie DC, Hebert PD. Genome-size evolution in fishes. Can J Fish Aquat Sci. 2004;61:1636-46

74. Dettaï A, Lecointre G. In search of notothenioid (Teleostei) relatives. Antarct Sci. 2004;16:71-85

75. Orsoly K, Virág K, Anita S, Zsuzsa E, Ágota A, György V, et al. Reliable transgene-independent method for determining Sleeping Beauty transposon copy numbers. 2011 [cited 2017 Apr 11]; Available from: https:// dea.lib.unideb.hu/dea/handle/2437/110559.
76. Kraaijeveld K, Zwanenburg B, Hubert B, Vieira C, De Pater S, Van Alphen JJM, et al. Transposon proliferation in an asexual parasitoid: Transposon proliferation. Mol Ecol. 2012;21:3898-906.

77. Lönnig W-E, Saedler H. Chromosome rearrangements and transposable elements. Annu Rev Genet. 2002;36:389-410.

78. Curcio MJ, Derbyshire KM. The outs and ins of transposition: from mu to kangaroo. Nat Rev Mol Cell Biol. 2003;4:865-77.

79. Splendore de Borba R, Lourenço da Silva E, Parise-Maltempi PP. Chromosome mapping of retrotransposable elements Rex 1 and Rex3 in Leporinus Spix, 1829 species (Characiformes: Anostomidae) and its relationships among heterochromatic segments and W sex chromosome. Mob Genet Elem. 2013;3(e27460)

80. Schneider CH, Gross MC, Terencio ML, Do Carmo EJ, Martins C, Feldberg E. Evolutionary dynamics of retrotransposable elements rex 1, rex 3 and rex 6 in neotropical cichlid genomes. BMC Evol Biol. 2013;13:1.

81. Rajeev L, Malanowska K, Gardner JF. Challenging a paradigm: the role of DNA homology in tyrosine recombinase reactions. Microbiol Mol Biol Rev. 2009;73:300-9.

82. Duncan L, Bouckaert K, Yeh F, Kirk DL. Kangaroo, a mobile element from Volvox carteri, is a member of a newly recognized third class of retrotransposons. Genetics. 2002;162:1617-30.

83. Slotkin RK, Martienssen R. Transposable elements and the epigenetic regulation of the genome. Nat Rev Genet. 2007;8:272-85.

84. Mazzuchelli J, Martins C. Genomic organization of repetitive DNAs in the cichlid fish Astronotus ocellatus. Genetica. 2009;136:461-9.

85. Capello J, Handelsman K, Lodish HF. Sequence of Dictyostelium DIRS-1: an apparent retrotransposon with inverted terminal repeats and an internal circle junction sequence. Cell. 1985;43:105-15.

86. Eickbush $\mathrm{TH}$, Jamburuthugoda VK. The diversity of retrotransposons and the properties of their reverse transcriptases. Virus Res. 2008;134:221-34.

87. Taillebourg E, Dura J-M. A novel mechanism for P element homing in Drosophila. Proc Natl Acad Sci. 1999;96:6856-61.

88. Biémont C, Vieira C. Genetics: junk DNA as an evolutionary force. Nature. 2006:443:521-4

89. Pimpinelli S, Berloco M, Fanti L, Dimitri P, Bonaccorsi S, Marchetti E, et al. Transposable elements are stable structural components of Drosophila melanogaster heterochromatin. Proc Natl Acad Sci. 1995;92:3804-8.

90. Ferreira DC, Porto-Foresti F, Oliveira C, Foresti F. Transposable elements as a potential source for understanding the fish genome. Mob Genet Elem. 2011;1:112-7.

91. Clark MS, Clarke A, Cockell CS, Convey P, Detrich HW III, Fraser KPP, et al. Antarctic genomics. Comp Funct Genomics. 2004;5:230-8.

92. Mazzei F, Ghigliotti L, Lecointre G, Ozouf-Costaz C, Coutanceau J-P, Detrich W, et al. Karyotypes of basal lineages in notothenioid fishes: the genus Bovichtus. Polar Biol. 2006;29:1071-6.

93. Mazzei F, Ghigliotti L, Coutanceau J-P, Detrich HW, Prirodina V, Ozouf-Costaz $C_{\text {, et }}$ al. Chromosomal characteristics of the temperate notothenioid fish Eleginops maclovinus (Cuvier). Polar Biol. 2008;31:629-34.

94. Nygren A, Edlund P, Hirsch U, Åhsgren L. Cytological studies in perch (Perca fluviatilis L.), pike (Esox lucius L.), pike-perch (Lucioperca lucioperca L.), and ruff (Acerina cernua L.). Hereditas. 1968:59:518-24.

95. Pisano E, Ozouf-Costaz C, Hureau JC, Williams R. Chromosome differentiation in the subantarctic Bovichtidae species Cottoperca gobio (Günther, 1861) and Pseudaphritis urvillii (Valenciennes, 1832)(Pisces, Perciformes). Antarct Sci. 1995;7:381-6.

96. Bourque $\mathrm{G}$. Transposable elements in gene regulation and in the evolution of vertebrate genomes. Curr Opin Genet Dev. 2009;19:607-12.

97. Winnepennincks B, Backeljau T, De Watcher R. Extraction of high molecular weight DNA from molluscs. Trends Genet. 1993;9:407.

98. Rey O, d'Hont A, Coutanceau JP, Pisano E, Chilmonczyk S, Ozouf-Costaz C. Cephalic kidney and spleen cell culture in Antarctic teleosts. Fish Cytogenet Tech Ray-Fin Fishes Chondrichthyans CRC Press Taylor Francis Group Lond. 2015:74-81.

99. Terrat $Y$, Bonnivard $E$, Higuet $D$. GalEa retrotransposons from galatheid squat lobsters (Decapoda, Anomura) define a new clade of Ty1/copia-like elements restricted to aquatic species. Mol Gen Genomics. 2008;279:63-73.

100. Hall T. BioEdit: a user-friendly biological sequence alignment editor and analysis program for windows 95/98/NT. Nucleic Acids Symp Ser. 1999; 41:95-8.

101. Altschul SF, Gish W, Miller W, Myers EW, Lipman DJ. Basic local alignment search tool. J Mol Biol. 1990;215:403-10. 
102. Shin SC, Ahn DH, Kim SJ, Pyo CW, Lee H, Kim M-K, et al. The genome sequence of the Antarctic bullhead notothen reveals evolutionary adaptations to a cold environment. Genome Biol. 2014;15:468.

103. Alva V, Nam S-Z, Söding J, Lupas AN. The MPI bioinformatics toolkit as an integrative platform for advanced protein sequence and structure analysis. Nucleic Acids Res. 2016;44:W410-5.

104. Katoh K, Standley DM. MAFFT multiple sequence alignment software version 7: improvements in performance and usability. Mol Biol Evol. 2013; 30:772-80.

105. Kearse M, Moir R, Wilson A, Stones-Havas S, Cheung M, Sturrock S, et al. Geneious basic: an integrated and extendable desktop software platform for the organization and analysis of sequence data. Bioinformatics. 2012;28:1647-9.

106. Castresana J. Selection of conserved blocks from multiple alignments for their use in phylogenetic analysis. Mol Biol Evol. 2000;17:540-52

107. Tamura K, Peterson D, Peterson N, Stecher G, Nei M, Kumar S. MEGA5: molecular evolutionary genetics analysis using maximum likelihood, evolutionary distance, and maximum parsimony methods. Mol Biol Evol. 2011:28:2731-9.

108. Milne I, Wright F, Rowe G, Marshall DF, Husmeier D, McGuire G. TOPALi: software for automatic identification of recombinant sequences within DNA multiple alignments. Bioinformatics. 2004;20:1806-7.

109. Jones DT, Taylor WR, Thornton JM. The rapid generation of mutation data matrices from protein sequences. Comput Appl Biosci CABIOS. 1992;8:275-82.

110. Stamatakis A. RAxML version 8: a tool for phylogenetic analysis and postanalysis of large phylogenies. Bioinformatics. 2014:30:1312-3.

111. Felsenstein J. Confidence limits on phylogenies: an approach using the bootstrap. Evolution. 1985;39:783.

112. Bonillo C, Coutanceau JP, D'Cotta H, Ghigliotti L, Ozouf-Costaz C, Pisano E. Standard fluorescence in situ hybridization procedures. Fish Cytogenet Tech Ray-Fin Fishes Chondrichthyans. 2015;103

113. Liehr T, editor. Fluorescence in situ hybridization (FISH) - application guide. Berlin: Springer; 2009.

114. Ozouf-Costaz C, Pisano E, Foresti F, de Almeida LF. Fish cytogenetic techniques: Ray-Fin fishes and chondrichthyans [Internet]. CRC Press; 2015 [cited 2017 Mar 16]. Available from: https://www.crcpress.com/FishCytogenetic-Techniques-Ray-Fin-Fishes-and-Chondrichthyans/Ozouf-CostazPisano-Foresti-Toledo/p/book/9781482211986.

115. Bustin SA, Benes V, Garson JA, Hellemans J, Huggett J, Kubista M, et al. The MIQE guidelines: minimum information for publication of quantitative realtime PCR experiments. Clin Chem. 2009;55:611-22.

116. Chen Z, Cheng C-HC, Zhang J, Cao L, Chen L, Zhou L, et al. Transcriptomic and genomic evolution under constant cold in Antarctic notothenioid fish. Proc Natl Acad Sci. 2008:105:12944-9.

117. Hardie DC, Hebert PD. The nucleotypic effects of cellular DNA content in cartilaginous and ray-finned fishes. Genome. 2003;46:683-706.

\section{Ready to submit your research? Choose BMC and benefit from:}

- fast, convenient online submission

- thorough peer review by experienced researchers in your field

- rapid publication on acceptance

- support for research data, including large and complex data types

- gold Open Access which fosters wider collaboration and increased citations

- maximum visibility for your research: over $100 \mathrm{M}$ website views per year

At BMC, research is always in progress.

Learn more biomedcentral.com/submissions 